\title{
Princípios Básicos de XAS e XPS
}

\author{
Emerson Schwingel Ribeiro \\ Maria Suzana P. Francisco \\ Yoshitaka Gushikem * \\ José Eduardo Gonçalves \\ gushikem@iqm.unicamp.br \\ Universidade Estadual de Campinas, Instituto de Química
}

Informações do Artigo

Histórico do Artigo

Criado em Fevereiro de 2003

\section{Palavras-Chaves}

Efeito fotoelétrico

Energia de ligação

Espectroscopia de Raios-X

Caracterização de materiais inorgânicos
Resumo

Os princípios básicos das espectroscopias de absorção e fotoeletrônica de raios-X (XAS e XPS) e seus principais equipamentos e métodos de tratamento de dados utilizados são introduzidos. É dada ênfase aos estudos das propriedades eletrônica e estrutural de materiais inorgânicos descrevendo alguns exemplos da literatura. Essas técnicas fornecem diferentes informações. A XPS permite a investigação da superfície, sendo principalmente usada na investigação de mudanças química e estrutural dos elementos presentes na superfície do material estudado. Por outro lado, a XAS fornece informações do volume (bulk) da amostra e sonda a ordem a curto alcance ao redor do átomo de interesse. Os exemplos descritos mostram que essas técnicas são complementares na caracterização de materiais.

\section{Introdução}

Diversas técnicas são utilizadas na caracterização de sólidos inorgânicos com o objetivo de obter informações estruturais, morfológicas, texturais de materiais inorgânicos. Para o estudo envolvendo o interior ou bulk das amostras podem ser citadas as espectroscopias no infravermelho ${ }^{1}$ e Raman, empregadas na investigação estrutural desses materiais e a espectroscopia de ressonância paramagnética eletrônica ${ }^{2}$ (Electron Paramagnetic Resonance, EPR) utilizada para obter informações eletrônicas e estruturais de espécies paramagnéticas, sendo por isso uma técnica bastante seletiva. Dentre as outras técnicas, como a espectroscopia de absorção de raios-X (X-Ray Absorption Spectroscopy, XAS) cita-se a XANES (X-Ray Absorption Near Edge Structure), que permite obter informações sobre o estado de oxidação do átomo fotoabsorvedor, o arranjo espacial dos átomos da sua vizinhança e a densidade de estados desocupados referente ao átomo fotoabsorvedor estudado [1], e a EXAFS (Extended X-Ray Absorption Fine Structure), que fornece informações estruturais de curto alcance, como o número de coordenação e as distâncias interatômicas ao redor do átomo estudado, permitindo uma estimativa da desordem local do sistema [1].

Para a caracterização da superfície dos sólidos inorgânicos, vários métodos espectroscópicos e microscópicos são utilizados, uma vez que o estudo das propriedades superficial tem grande importância para diversas áreas, tais como catálise heterogênea, semicondutores, mecanismos de corrosão, atividade de superfícies metálica, propriedades ácidas de óxidos mistos, estudos e comportamento de membranas biológicas, cerâmicas, vidros etc.

Dentre as técnicas espectroscópicas, a de fotoelétrons 
excitados por raios-X (X-Ray Photoelectron Spectroscopy, XPS, também conhecida por Electron Spectroscopy for Chemical Analysis, ESCA) é uma das mais utilizadas [2]. Esta técnica fornece dados sobre a composição atômica da superfície, a identificação elementar, o estado químico e o número de coordenação dos átomos locados próximos a superfície da amostra. A técnica espectroscópica de elétrons Auger ${ }^{3}$ (Auger Electron Spectroscopy, AES) é empregada na análise qualitativa da superfície dos sólidos; outras técnicas espectroscópicas também podem ser utilizadas como a espectroscopia fotoeletrônica no ultravioleta ${ }^{4}$ (Ultraviolet Photoelectron Spectroscopy, UPS), a espectrometria de massa de íons secundários $^{5}$ (Secondary Ion Mass Spectrometry, SIMS), a espectrometria de massa de microssonda laser ${ }^{6}$ (Laser Microprobe Mass Spectrometry, LMMS) e a microssonda eletrônica ${ }^{7}$ (Electron Microprobe, EM).

Para a análise de superfície envolvendo métodos microscópicos ${ }^{8}$ existem diferentes técnicas microscópicas como a de eletrônica de varredura' ${ }^{9}$ (Scanning Electron Microscopy, SEM), tunelamento (Scanning Tunneling Microscopy, STM) e a de força atômica ${ }^{10}$ (Atomic Force Microscopy, AFM), sendo estas utilizadas para análises qualitativa e quantitativa da composição atômica da superfície, bem como para estudos morfológicos dos materiais [3].

As técnicas de XPS e XAS tornaram-se mais populares nas últimas décadas devido aos recentes avanços tecnológicos, tais como o desenvolvimento de instrumentação e de "softwares" necessários para a obtenção e processamento dos dados e também, à ampliação do conhecimento dos princípios físicos envolvidos e da matemática envolvida, que levaram a uma análise e interpretação mais precisa dos dados experimentais [4-9]. As análises por XPS necessitam que a superfície investigada esteja livre de gases absorvidos, por isso o desenvolvimento de sistemas de ultra-alto vácuo (UHV) foi de grande importância [4-6, 10,11]. No caso da técnica de XAS, a utilização da luz síncrotron ${ }^{11}$ [12-14] possibilitou um grande salto no uso dessas técnicas, uma vez que a fonte de luz síncrotron gera elétrons de alta energia $\left(\mathbf{E}>\mathbf{1} \mathbf{G e V}^{\mathbf{1 2}}\right)$, essencial para se obter espectros com uma boa relação sinal/ruído. A fonte luz é o conjunto de equipamentos que, operados de maneira simultânea, gera a luz síncrotron. Até meados dos anos 80, a utilização de XAS era limitada pela baixa energia das fontes convencionais de radiação contínua e fluxo de fótons sobre a amostra, em geral seis vezes menor.

O presente texto tem como objetivo introduzir os princípios básicos das técnicas de XPS eXAS, os principais equipamentos utilizados, noções sobre o tratamento de dados e preparação de amostras. Adicionalmente, alguns exemplos da literatura contendo estudos estruturais de sólidos inorgânicos são descritos com o intuito de exemplificar as diferentes informações que cada técnica pode fornecer e a complementaridade entre elas.

\section{A técnica de XPS}

\section{Princípio Básico - O Efeito Fotoelétrico}

O princípio básico da técnica de XPS (espectrocopia fotoeletrônica de raios-X) é o efeito fotoelétrico que pode ser explicado através do diagrama de níveis de energia mostrado na Figura 1.

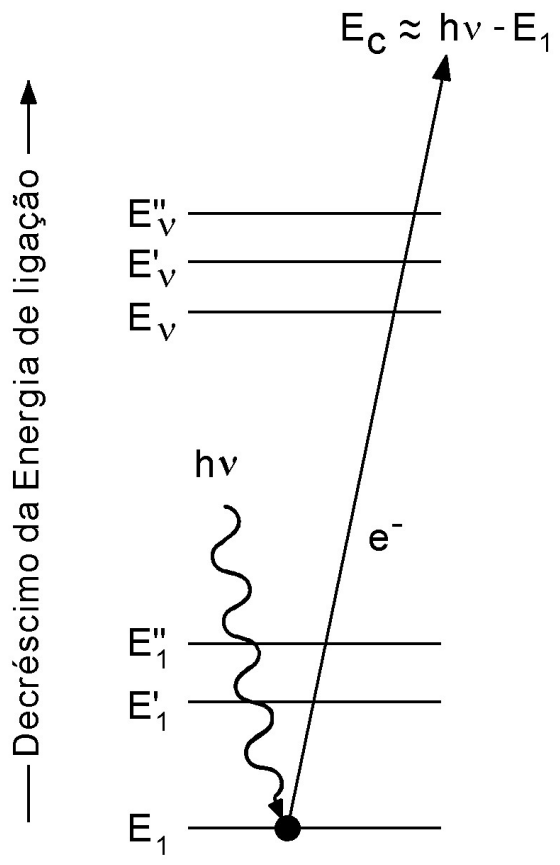

Figura 1 - Representação esquemática do processo XPS, onde, as três linhas de baixo, $E_{1}, E_{1}^{\prime} E^{\prime}$, representam as energias dos elétrons das camadas mais internas $\mathrm{K}$ e $\mathrm{L}$ de um átomo, e as três linhas de cima, $\mathrm{Ev}$, E'v e E'v, representam alguns dos níveis de energia de outros elétrons de valência ou de uma camada [16].

A energia transportada por um fóton de raios-X (hv) é absorvida pelo átomo alvo, levando a origem do estado excitado, que é relaxado pela emissão de um fotoelétron (ionização de átomo) proveniente das camadas eletrônicas mais internas (cerne) do átomo.

A energia cinética $\mathrm{E}_{\mathrm{c}}$ do fotoelétron que deixa o átomo alvo depende da energia do fóton incidente, hv, e é expressa pela lei fotoelétrica de Einstein, 


$$
\mathrm{E}_{\mathrm{c}}=\mathrm{h} v-\mathrm{E}_{1}-\phi
$$

onde $\mathrm{E}_{1}$ é a energia de ligação do fotoelétron com relação ao nível de Fermi e $\phi$ é a função-trabalho do espectrômetro, que é um fator que corrige o meio eletrostático em que o elétron é formado e medido [14]. Em XPS mede-se a intensidade de fotoelétrons $\mathrm{N}(\mathrm{E})$ como função de suas energias cinéticas $\left(\mathrm{E}_{\mathrm{c}}\right)$. Porém, os espectros de XPS são usualmente apresentados na forma de gráficos, no qual $\mathrm{N}(\mathrm{E})$ é uma função de $\mathrm{E}_{1}$.

Uma técnica torna-se sensível à superfície se a radiação a ser detectada não "viajar" mais do que algumas camadas atômicas ( 0,5 a 3,0 nm) através dos sólidos. Os elétrons com energia cinética entre 10 e $1500 \mathrm{eV}$ são ideais ao estudo de superfícies, pois seus caminhos livres médios nos sólidos são daquela ordem [14, 15]. Em XPS, os fotoelétrons possuem energia cinética na faixa de $100 \mathrm{a}$ $1400 \mathrm{eV}$, e quando gerados próximos a superfície tornam esta técnica bastante adequada ao estudo da superfície de sólidos $[2,16]$.

Os elementos presentes na superfície da amostra são caracterizados diretamente pela determinação das energias de ligação dos picos fotoelétricos. Isso se dá pelo fato de que os níveis de energia do processo de fotoemissão são quantizados, sendo assim os fotoelétrons possuem uma distribuição de energia cinética de picos discretos relativos às camadas eletrônicas do átomo fotoionizado. Informações sobre a composição superficial da amostra são obtidas através da área integrada do pico, que é proporcional ao número de átomos no volume detectado [17].

Os picos dos fotoelétrons são rotulados segundo os números quânticos do nível do qual o elétron se origina $[2,14]$. Um elétron com momento angular orbital L $(s, p$, $d, f$ etc) e momento angular de spin $\mathrm{S}$ tem um momento angular orbital total $\mathrm{J}=\mathrm{L}+\mathrm{S}$. Cada nível com $\mathrm{J} \geq 1$ tem dois sub-níveis, pois $S= \pm 1 / 2$, com uma separação de energia conhecida por separação spin-órbita. Por exemplo, o elétron do nível $2 \mathrm{p}$ do cobre origina dois picos de fotoemissão, $2 \mathrm{p}_{3 / 2}(\operatorname{com} \mathrm{L}=1, \mathrm{~J}=1+1 / 2)$ e $2 \mathrm{p}_{1 / 2}(\operatorname{com~L}=1$, $\mathrm{J}=1-1 / 2)$. A intensidade relativa dos picos é determinada pela multiplicidade dos níveis correspondentes igual a $2 \mathrm{~J}$ +1 . Portanto, a intensidade relativa das componentes $\mathrm{J}=$ $1 / 2$ e $\mathrm{J}=3 / 2$ do dubleto do cobre é $2: 4$.

As energias de ligação são não somente específicas para cada elemento como também contêm informações químicas, pois os níveis de energia dos elétrons de caroço dependem fracamente do estado químico do átomo. Estes deslocamentos químicos estão tipicamente no intervalo de $0-3 \mathrm{eV}[2,17]$. Estes deslocamentos químicos podem ser explicados assumindo que a atração do núcleo por um elétron interno é diminuída pela presença de outros elétrons. Quando um desses elétrons é removido, a carga efetiva sentida por um elétron interno é aumentada, ocorrendo assim um aumento nas energias de ligações $[10,18,19]$. Por exemplo, no caso do titânio contido nos óxidos $\mathrm{TiO}_{2}(\mathrm{Ti}(\mathrm{IV}))$ e $\mathrm{Ti}_{2} \mathrm{O}_{5}(\mathrm{Ti}(\mathrm{V}))$, os 18 elétrons do $\mathrm{Ti}(\mathrm{IV})$ sentem uma maior força de atração do núcleo com uma carga positiva igual a 22 do que os 19 elétrons do íon $\mathrm{Ti}$ (III) de mesma carga positiva 22. Lu e colaboradores [20] atribuíram as posições dos picos $2 \mathrm{p}_{3 / 2}$ do titânio às energias de ligações 458,8, 457,5 e 455,1 eV para $\mathrm{TiO}_{2}$, $\mathrm{Ti}_{2} \mathrm{O}_{3}$ e $\mathrm{TiO}$, respectivamente, encontrados na superfície policristalina de titânio metálico após tratamentos específicos.

A análise das energias de ligação do material deve ser acompanhada da análise de um padrão para que sejam avaliados os deslocamentos químicos oriundos de outros efeitos, tais como o carregamento nas superfícies isolantes e as variações na função-trabalho, cuja teoria ainda não esta bem estabelecida $[10,11,17,21]$.

Os picos fotoelétricos são superpostos por um fundo (background). Este background resulta de fotoelétrons produzidos dentro do ânodo da fonte de raios-X, que estiveram sujeitos a um ou mais processos de espalhamento inelástico antes de serem emitidos da superfície $[4,17]$.

A presença de um buraco interno após a ionização afeta a distribuição dos elétrons emitidos, levando a deslocamentos, separação de picos e o surgimento de picos satélites [17]. Os picos satélites chamados de shake up e shake off correspondem a efeitos dos estados finais que se originam quando o fotoelétron concede energia a um outro elétron do átomo [2]. Este elétron vai para um estado não ocupado (shake up) ou não ligado (shake off) de maior energia. Como conseqüência, o fotoelétron perde energia cinética e aparece a um maior valor de energia de ligação no espectro. Por exemplo, no caso do cobre, as características dos picos shake up dos níveis $2 \mathrm{p}_{3 / 2}$ e $2 \mathrm{p}_{1 / 2}$ são o diagnóstico de uma camada $3 \mathrm{~d} 9$ não ocupada no $\mathrm{Cu}^{2+}[22]$.

A Figura 2 ilustra um espectro exploratório (chamado long scan) de XPS.

Este espectro mostra picos provenientes de uma amostra contendo vários componentes suportados sobre alumina, utilizando radiação do ânodo de magnésio [23]. Notase que as interferências por superposição de picos são insignificantes, pois os picos tendem a ser bem separados, até mesmo no caso de elementos adjacentes na tabela 


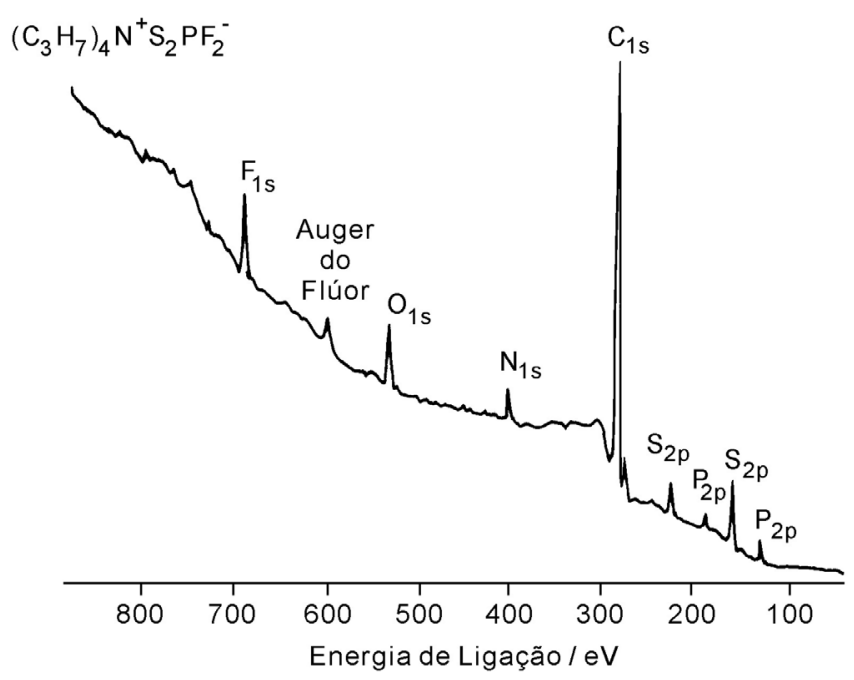

Figura 2 - Espectro exploratório de XPS de uma amostra contendo vários componentes suportados sobre alumina [23].

periódica como o carbono, nitrogênio, oxigênio e alumínio. Observa-se que as energias de ligação para os elétrons 1s aumentam com o número atômico, pois há um aumento da carga positiva do núcleo $\left(\mathrm{C}_{1 \mathrm{~s}}<\mathrm{N}_{1 \mathrm{~s}}<\mathrm{O}_{1 \mathrm{~s}}\right)$, e que mais de um pico para um dado elemento pode ser observado, que é o caso do enxofre e do alumínio que apresentam picos para os elétrons dos níveis $2 \mathrm{~s}$ e $2 \mathrm{p}$ (este com as duas componentes spin-órbita $2 \mathrm{p}_{3 / 2}$ e $2 \mathrm{p}_{1 / 2}$ ).

\section{Energia de Ligação e Estado Final}

Na prática, os dados de XPS são usados como se fossem característicos dos átomos como estão antes do evento do efeito fotoelétrico acontecer. Porém, os dados de fotoemissão representam um estado no qual o elétron acabou de deixar o átomo [15, 24].

Considerando um átomo contendo $\mathrm{N}$ elétrons, com energia total $\mathrm{E}_{\mathrm{N}}{ }^{\mathrm{i}}$ no estado inicial i. O átomo absorve um fóton de energia $h v$, o evento de absorção ocorre em menos de $10^{-17} \mathrm{~s}$. Após $10^{-14} \mathrm{~s}$, o átomo emite um fotoelétron com uma dada energia cinética $\mathrm{E}_{\mathrm{c}}$ e passa para um estado final com um elétron a menos e um buraco no nível interno. $\mathrm{O}$ balanço da energia deste evento é:

$$
\mathrm{E}_{\mathrm{N}}{ }^{\mathrm{i}}+\mathrm{h} v=\mathrm{E}_{\mathrm{N}-1,1}{ }^{\mathrm{f}}+\mathrm{E}_{\mathrm{c}}
$$

onde, $\mathrm{E}_{\mathrm{N}}{ }^{\mathrm{i}}$ é a energia total de um átomo com $\mathrm{N}$ elétrons no estado inicial, isto é, antes da fotoemissão ocorrer e $\mathrm{E}_{\mathrm{N}-1,1}{ }^{\mathrm{f}}$ é a energia total do átomo com $\mathrm{N}-1$ elétrons e um buraco no nível 1 , no estado final. O rearranjo dos termos mostra que a energia de ligação com relação ao nível de Fermi é:

$$
\mathrm{E}_{1}=\mathrm{h} v-\mathrm{E}_{\mathrm{c}}-\phi=\mathrm{E}_{\mathrm{N}-1,1}^{\mathrm{f}}-\mathrm{E}_{\mathrm{N}}{ }^{\mathrm{i}}-\phi
$$

Os N-1 elétrons remanescentes no estado final do átomo, assim como os elétrons dos átomos da vizinhança, sentem a ausência do elétron do caroço (ou seja, sentem a presença do buraco do caroço). Como resultado, eles relaxam para uma energia total menor do átomo de uma quantidade $\Delta \mathrm{E}_{\text {relax }}$. Esta energia de relaxação, que tem contribuições intra e extra atômicas, está incluída na energia cinética do fotoelétron. Então, a energia de ligação não é igual à energia do orbital do qual o fotoelétron é emitido e a diferença é causada pela reorganização dos elétrons remanescentes quando um elétron é removido de uma camada mais interna (elétron de caroço). Como conseqüência, a energia de ligação de um fotoelétron contém informação do estado do átomo antes da fotoinização (estado inicial) e do átomo ionizado depois da emissão do elétron (estado final).

O espectro de XPS do nível 3d do cério contido em $\mathrm{CeO}_{2}$ é um bom exemplo de como o estado final do átomo influencia nos dados de fotoemissão. $O$ estado fundamental do $\mathrm{CeO}_{2}$ é uma mistura das configurações multi-eletrônicas $4 \mathrm{f}^{0} \mathrm{e}^{4} \mathrm{f}^{1} \underline{\mathrm{L}}$, onde $\underline{\mathrm{L}}$ denota um buraco nos orbitais $2 \mathrm{p}$ do oxigênio $[25,26]$. Os dubletos $3 \mathrm{~d}_{5 / 2} \mathrm{e}$ $3 \mathrm{~d}_{3 / 2}$ são geralmente denominados u e v e se estendem no intervalo de 880 a $920 \mathrm{eV}$. Para o $\mathrm{CeO}_{2}$, os estados finais decorrentes da fotoemissão do nível $3 \mathrm{~d}$ do Ce originam seis picos correspondentes aos três pares dos dubletos spinórbita $\left(3 \mathrm{~d}_{5 / 2}\right.$ e $\left.3 \mathrm{~d}_{3 / 2}\right)$, decorrentes das diferentes ocupações do estado final $4 \mathrm{f}$ do Ce fortemente hibridizados com os orbitais 2 p do oxigênio. Os picos v e v" são atribuídos aos estados antiligante e ligante da mistura das configurações eletrônicas $3 \mathrm{~d}^{9} 4 \mathrm{f}^{2}\left(\mathrm{O} 2 \mathrm{p}^{4}\right)$ e $3 \mathrm{~d}^{9} 4 \mathrm{f}^{1}\left(\mathrm{O} 2 \mathrm{p}^{5}\right)$ do $\mathrm{Ce}(\mathrm{IV})$ e v" ao estado final $3 \mathrm{~d}^{9} 4 \mathrm{f}^{0}\left(\mathrm{O} 2 \mathrm{p}^{6}\right)$ do $\mathrm{Ce}(\mathrm{IV})$ $[25,26]$. A mesma explicação foi dada a série de estruturas u. Portanto, o espectro final do $\mathrm{CeO}_{2}$ é composto de seis picos fotoelétricos como mostrado na Figura 3.

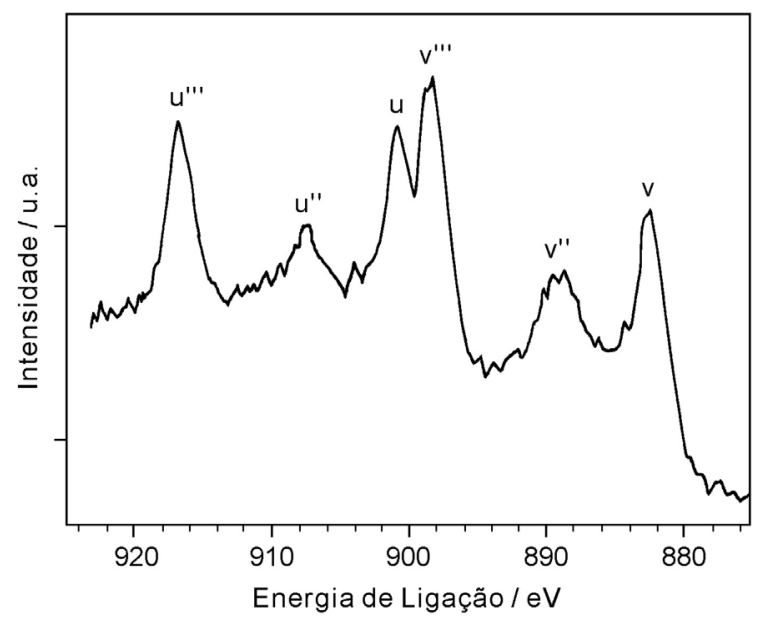

Figura 3 - Espectros de XPS do nível3d do Ce do $\mathrm{CeO} 2$ [26]. 


\section{Equipamentos}

Basicamente um equipamento de XPS é composto de uma câmara de ultra-alto vácuo (ultra high vacuum, UHV), uma fonte de raios-X, um canhão de íons, um manipulador de amostra, um espectrômetro, um detector de elétrons e um computador para aquisição e tratamento de dados. Obviamente que dependendo do equipamento utilizado, a sua configuração pode mudar dependendo dos diferentes acessórios que podem compô-lo.

Como citado anteriormente, é necessário utilizar a câmara de UHV para que a superfície a ser analisada esteja livre de gases adsorvidos e de contaminantes. Isso se dá pelo fato de que os elétrons podem colidir com moléculas de gases residuais, necessitando assim de um livre caminho médio suficiente $\geq 10 \mathrm{~cm}$ para atingir a amostra ou o detector, sendo necessárias pressões menores que $10^{-5}$ $\mathrm{Pa}$. Para uma pressão da câmara de UHV igual a $10^{-12}$ $\mathrm{Pa}$ leva-se aproximadamente $10^{4}$ segundos até que uma monocamada seja adsorvida sobre uma superfície [10, 17, 27]. As bombas mais utilizadas para se atingir a condição de UHV na câmara são a bomba de difusão ${ }^{13}$ (ou mecânica), a bomba turbo-molecular ${ }^{14}$ e a bomba iônica $[17,28]$.

Em geral, as amostras são introduzidas dentro do ambiente da câmara do UHV através de sistemas tipo air-lock $\boldsymbol{k}^{15}$ que permitem uma transferência em questão de segundos [4]. O principal contaminante da superfície de uma amostra colocada na câmara é o carbono, além do oxigênio, cloro, enxofre, cálcio e nitrogênio [17]. O bombardeamento sobre a superfície por íons de gases inertes, como, por exemplo, o de $\mathrm{Ar}^{+}$, pode ser feito com o propósito de obter uma superfície mais limpa, o aquecimento também pode ser utilizado. Outros métodos de limpeza da superfície a ser analisada envolvem a fratura de materiais frágeis em UHV e tratamentos químicos a temperaturas elevadas sob pressão parcial de $\mathrm{O}_{2}$ ou $\mathrm{H}_{2}$ [29].

A fonte de fótons em um equipamento de XPS gera raios-X moles (de baixa energia) produzidos a partir de um ânodo de alumínio ou de magnésio. Para o caso do alumínio, o intervalo do espectro de raios- $X$ utilizado é $0-1200 \mathrm{eV}$ e para o magnésio $0-1400 \mathrm{eV}$. A Figura 4 mostra a dependência do livre caminho médio de diferentes materiais para o espalhamento inelástico em função de sua energia cinética, chamada de "curva universal", que exibe uma região de mínimo na faixa de 10-500 eV, correspondendo a um livre caminho médio entre 0,4 e $2 \mathrm{~nm}[4,15]$. O livre caminho médio em combinação com a orientação da emissão fotoelétrica dá origem à chamada "profundidade de escape" na ordem de
2-10 monocamadas atômicas do material analisado.

O analisador de elétrons mais usado em XPS é o analisador hemisférico concêntrico (concentric hemispheric analyser, CHA). Para muitos materiais uma alta resolução em energia de elétrons $(<0,1 \mathrm{eV})$ é necessária na análise da superfície para que os deslocamentos químicos sejam medidos com precisão.

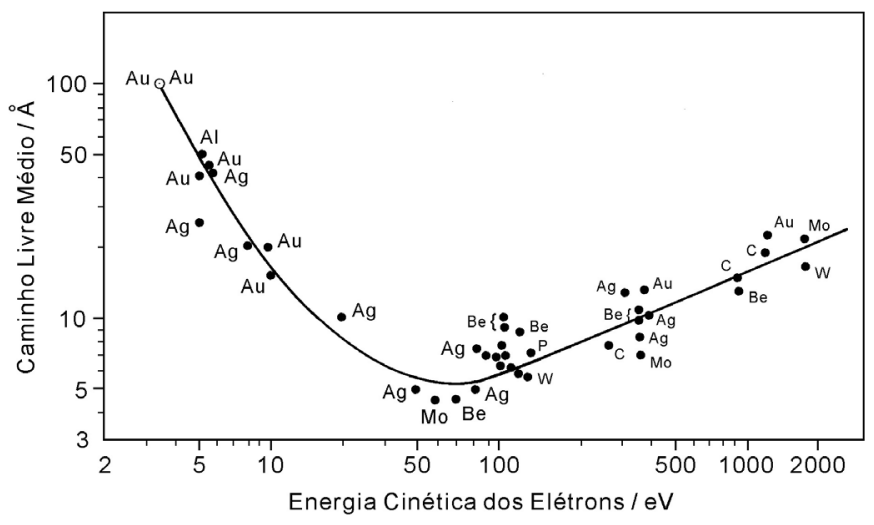

Figura 4 - "Curva universal" para o livre caminho médio em função da energia cinética dos elétrons. Os pontos indicam medidas individuais [16].

A Figura 5 exibe o esquema de um equipamento de XPS, no qual a configuração do sistema de UHV é composta por duas câmaras isoladas por uma válvula.

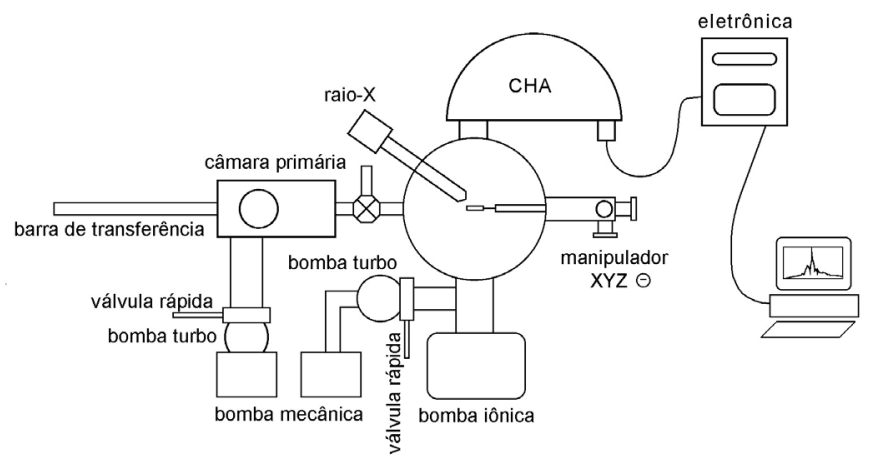

Figura 5 - Esquema de um equipamento de XPS do grupo de Física de Superfícies da Unicamp [30].

A câmara primária é dedicada à transferência de amostras da atmosfera para a segunda câmara (câmara principal), praticamente sem alterar o vácuo desta última. Na parte inferior está o sistema de bombeamento composto por duas bombas turbo-moleculares com bombeamento primário realizado por bombas mecânicas. Este bombeamento turbo-molecular permite obter pressões da ordem 10${ }_{10} \mathrm{~Pa}$. Por último uma bomba iônica é utilizada para bombear isoladamente a câmara principal, que propicia uma pressão residual próxima de $10^{-12} \mathrm{~Pa}$. A câmara principal é dedicada exclusivamente a análise de amostras, 
e é equipada com um tubo de raios-X, um canhão de íons para gases inertes, um manipulador $X Y Z \Theta$ que permite um ajuste fino da posição da amostra, um sistema de aquecimento da amostra e um analisador $\mathrm{CHA}$ equipado com um detector de elétrons do tipo channeltron ${ }^{16}[30]$.

\section{A técnica de XAS}

\section{Princípio Básico - $\mu(\mathrm{E})$}

A espectroscopia de absorção de raios-X (XAS) mede o coeficiente de absorção dos raios-X, $\mu(\mathrm{E})$, como uma função da energia da radiação incidente, $E=h v$. Quando um feixe de fótons de raios- $X$ atravessa um material com, a intensidade do raio incidente, $\mathrm{I}_{0}$, decresce de uma quantidade que é dependente das características de absorção do material sendo irradiado. Para uma trajetória da radiação através do material cujo comprimento é $\mathrm{dx}$, o decréscimo $\mathrm{dI}$ é dado por $\mathrm{dI}=-\mu(\mathrm{E}) \mathrm{Idx}$. Integrando a equação sobre a espessura total $\mathrm{x}$, obtém-se a Lei de BeerLambert,

$$
I_{t}=I_{0} e^{-\mu(E) x}
$$

onde $\mathrm{I}_{\mathrm{t}}$ é a intensidade do feixe transmitido.

O processo básico de XAS consiste na excitação de elétrons localizados nos níveis mais próximos do caroço ( $\mathrm{K}$ ou $\mathrm{L}$, no caso de raios-X) do átomo absorvedor (isto é, o átomo que absorve a energia dos elétrons de raios-X) através da absorção de raios-X. As transições eletrônicas causadas pela absorção de energias menores que a energia de ligação, só ocorrem quando o átomo absorvedor possuir estados localizados não ocupados ou parcialmente desocupados, onde essa faixa de absorção denomina-se região de pré-borda. Se a energia do fóton incidente é suficiente para arrancar os elétrons localizados nos níveis internos, então a absorção deixa de decrescer gradualmente com o aumento de energia e aumenta drasticamente, observando-se um salto no espectro de absorção. Esse aumento verificado no espectro é denominado de borda de absorção, e a energia onde ocorre a absorção depende da energia de ligação dos elétrons ao átomo e, portanto é uma característica de cada elemento químico. Ou seja, quando ocorre a absorção de energia maior que a energia de ligação, ocorre transição para o estado contínuo, não localizado no átomo absorvedor, e o excesso de energia é carregado pelo fotoelétron na forma de energia cinética [31-34]. Quando os elétrons ligados ao cerne do átomo fotoabsorvedor pertencem à camada 1 s, a borda é chamada de borda-K, e para o caso da camada $2 \mathrm{p}$ a correspondente borda é chamada de borda-L.

No caso de átomos isolados (no estado gasoso) ou de não haver nenhum vizinho suficientemente próximo após a borda de absorção, verifica-se uma queda suave na absorção até a próxima borda de absorção. Quanto a sistemas condensados (estado sólido ou líquido), após a borda de absorção são observadas oscilações no coeficiente de absorção $\mu(E)$ que se superpõem ao decaimento monotônico do coeficiente de absorção, conforme esquematizado na Figura 6. Essas oscilações são explicadas como sendo resultado da interferência entre a função de onda do fotoelétron e o retroespalhamento dessa função de onda pelos átomos vizinhos ao átomo fotoabsorvedor.

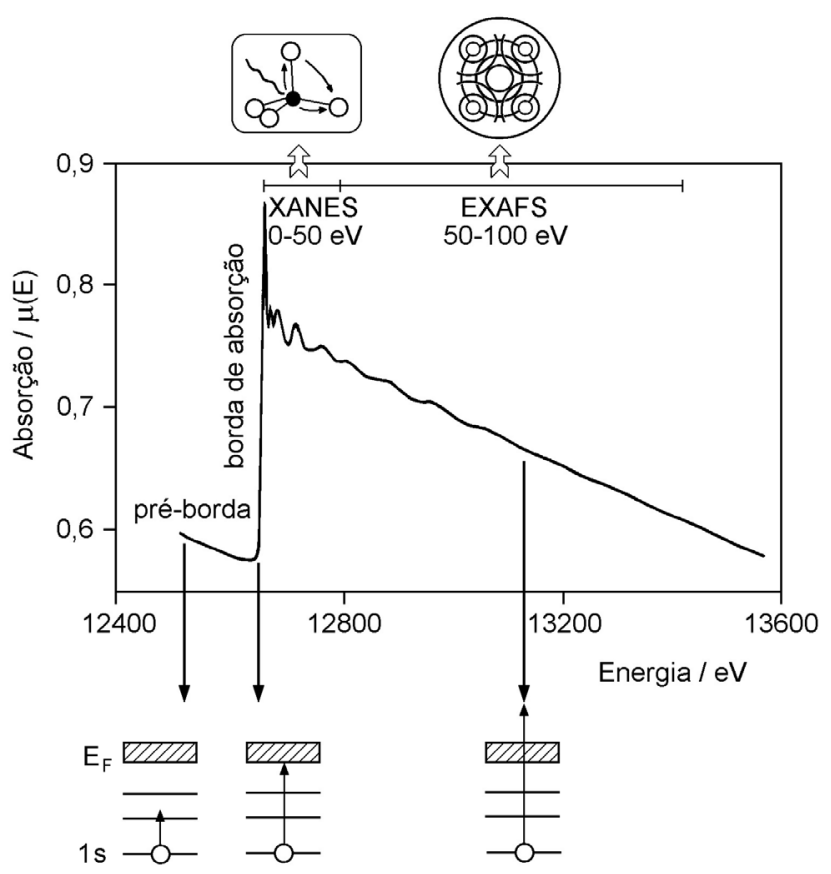

Figura 6 - Espectro de absorção de raios-X da borda K do selênio e representação das transições eletrônicas que correspondem as características básicas do espectro, a pré-borda e as regiões de XANES e EXAFS) [66].

\section{Espectros XANES e EXAFS}

Após a borda de absorção (Figura 6), o espectro é dividido em duas regiões:

(1) A Região de XANES é compreendida até a faixa de $50 \mathrm{eV}$ acima da borda de absorção, a qual apresenta variações estreitas e intensas da absorção. A análise teórica do espectro XANES envolve a solução da equação de Schrödinger para um intervalo de baixa energia, no qual 
a interação do elétron com o átomo é muito forte. Mais especificamente, o elétron é ejetado para um estado a apenas algumas dezenas de $\mathrm{eV}$ acima da energia de Fermi, com energia cinética baixa e livre caminho médio grande, favorecendo processos de espalhamentos múltiplos ${ }^{17}$ (MS) inelásticos do fotoelétron [35]. Portanto, a interação de muitos corpos, espalhamentos múltiplos, distorção da função de onda do estado excitado pelo campo de Coulomb $^{18}$ etc, são efeitos de grande importância nas características do espectro XANES.

Devido a estes efeitos, e principalmente, ao espalhamento inelástico do elétron excitado e ao tempo de vida finito do buraco do caroço, somente um grupo (cluster) de tamanho finito é relevante para determinar o estado final da onda do fotoelétron. As mudanças ao redor da distribuição de carga de um dado átomo em ambientes químicos diferentes podem alterar as energias dos níveis do caroço, produzindo mudanças na borda de absorção que se destacam nesta região do espectro $[1,35,36]$. Assim, o espectro fornece informações sobre o arranjo espacial dos átomos da vizinhança do átomo absorvedor, seu estado de oxidação, a densidade de estados desocupados do átomo absorvedor etc.

A teoria de XANES ainda não é completamente quantitativa devido a consideração do espalhamento múltiplo do fotoelétron [31, 34-37]. Embora o espectro XANES seja objeto de muitas investigações, não existe um completo entendimento.

(2) A Região de EXAFS compreende a absorção de energia que ocorre na faixa de 50 a $1000 \mathrm{eV}$ acima da borda de absorção, apresentando oscilações mais suaves na absorção. No espectro EXAFS, considera-se o envolvimento de apenas doisátomos, um absorvedor e outro retroespalhador. No limite de EXAFS, de alta energia, a interação entre os elétrons e os átomos vizinhos tornase menos intensa. Em altas energias, o espalhamento dos elétrons excitados é bastante fraco, que uma contribuição significativa para a função de onda do estado final nas proximidades do átomo absorvedor é devida à trajetória na qual o elétron é espalhado somente uma única vez antes de retornar ao átomo absorvedor (espalhamento simples ${ }^{17}$ ). Uma vez que o regime EXAFS é dominado pelo espalhamento simples, a informação que o mesmo contém é puramente geométrica e mais facilmente extraída que as contidas nos espectros XANES.

\section{A Fórmula $\operatorname{EXAFS~}(\chi(\mathrm{k}))$}

$\mathrm{Na}$ borda de absorção, a energia cinética do elétron $\mathrm{E}_{\mathrm{c}}$ é definida por E0, freqüentemente referida como energia do ponto-zero ou potencial interno. A energia cinética do fotoelétron ejetado é dada por $\mathrm{E}_{\mathrm{c}}=\mathrm{h} v-\mathrm{E}_{1}$ ou em termos de onda esférica ( $\mathrm{k}$ ) é dada por,

$$
k=\sqrt{\left(\frac{8 \pi^{2} m}{h^{2}}\right)\left(h v+E_{0}-E_{\text {edge }}\right)}
$$

onde $v$ é a freqüência de propagação relativa ao comprimento de onda $\lambda$ do raios-X, definidos como $v=$ $\mathrm{c} / \lambda$ e $\lambda=2 \pi / \mathrm{k}$, sendo $\mathrm{c}$ a velocidade da $\mathbf{l u z}{ }^{19}, \mathrm{~m}$ a massa do elétron e h a constante de Plank ${ }^{20}$.

O coeficiente de absorção linear $\mu(\mathrm{E})$ é proporcional a probabilidade de transição do efeito fotoelétrico. Segundo a Regra de Ouro de Fermi ${ }^{21}$, a probabilidade de transição (dentro da aproximação dipolar) é uma função das funções de onda do estado inicial e do estado final

$$
\mu(E)=C\left|\left\langle\psi_{f}|\hat{r} r| \psi_{i}\right\rangle\right| 2 \delta\left(E_{f}-E_{i}-h v\right)
$$

onde ê é o vetor campo elétrico polarizado do fóton e $\mathrm{r}$ o vetor coordenada do elétron [36]. A função de onda do estado final $\Psi_{f}$ do elétron fotoejetado consiste de duas partes principais; a onda eletrônica que deixa o átomo absorvedor, $\Psi_{\text {outgoing }}$, e a onda eletrônica que é retroespalhada pelos átomos da vizinhança, $\Psi_{\text {backscattered }}$, $\Psi_{\mathrm{f}}=\Psi_{\text {outgoing }}+\Psi_{\text {backscattered }}$. A interferência entre estas duas funções de onda do estado final leva a observação da estrutura fina no espectro de absorção de raios-X, que são as variações senoidais do coeficiente de absorção, $\mu(E)$, em função da energia do fóton incidente, conhecidas como oscilações EXAFS.

A amplitude de cada oscilação de EXAFS depende do número de coordenação (número de átomos vizinhos) e do poder de espalhamento do átomo vizinho, bem como do seu tipo de ligação e da distância ao átomo absorvedor. Nas oscilações EXAFS, os picos correspondem à onda retroespalhada em fase com a parte que deixa o átomo absorvedor (interferência construtiva), enquanto que os vales aparecem quando as duas estão fora de fase (interferência destrutiva).

O coeficiente de absorção acima da borda de absorção é definido como

$$
\mu_{\text {total }}=\mu_{0}\left[1+\chi_{\mathrm{EX}}\right]
$$

com $\mu_{0}$ representando o background atômico e $\chi_{\mathrm{EX}}$ formando a parte oscilatória da absorção total, que é a 


\section{função EXAFS.}

A função $\chi$ éa soma de ondas individuais devido a diferentes tipos de átomo da vizinhança ou diferentes distâncias do mesmo tipo de vizinhos. A validade da teoria da ordem a curto alcance de Kroning foi bastante implementada por Sayers e colaboradores [32] que desenvolveram a parametrização quantitativa de EXAFS, que se tornou padrão para muitos trabalhos correntes, e como resultado obtiveram a equação $[1,36]$ :

$$
\chi(k)=\sum_{i=1}^{\text {esferas }} A_{i}(k) \operatorname{sen}\left(2 k R_{i}+2 \delta(k)+\phi_{i}\right)
$$

No espaço k, cada onda é caracterizada por uma amplitude moduladora,

$$
A_{i}(k)=N_{i} \frac{e^{-2 R_{i} / \lambda(k)}}{k R_{i}^{2}} S_{o}^{2} f_{i}(k) e^{-2 \sigma_{i}^{2} k^{2}}
$$

onde,

$\mathrm{k}$ : módulo vetor de onda do fotoelétron criado no processo de fotoabsorção;

$\chi(\mathrm{k})$ : coeficiente de absorção normalizado;

i : índice referente a cada esfera de coordenação do átomo estudado;

$\mathrm{R}_{\mathrm{i}}$ : distância entre o átomo i e o átomo absorvedor;

$\delta(\mathrm{k})$ : defasagem devida ao átomo absorvedor;

$\phi_{\mathrm{i}}$ : defasagem devida ao átomo vizinho.

$\mathrm{N}_{\mathrm{i}}$ : número de átomos do tipo $\mathrm{i}$;

$\mathrm{S}_{0}{ }^{2}$ : fator de redução da amplitude devido a efeitos de correlação eletrônica;

$\lambda(\mathrm{k})$ : livre caminho médio do fotoelétron;

$\mathrm{f}_{\mathrm{i}}(\mathrm{k})$ : amplitude (ou performance) de retroespalhamento do fotoelétron pelo átomo vizinho i;

$\mathrm{e}^{-2 \sigma_{i}^{2} k^{2}}$ : fator de Debye Waller.

Nessa expressão distingue-se dois grupos de parâmetros: os estruturais $N_{i}, R_{i}$ e $\sigma_{i}$ e os atômicos $\lambda, f_{i}(k), \delta(k)$ e $\phi_{i}$.

A dependência da estrutura oscilatória com a distância interatômica e a energia está refletida no termo sen $(2 \mathrm{kRi})$. Uma maior contribuição à fase total $\left(2 \delta(\mathrm{k})+\phi_{\mathrm{i}}\right)$ é dada pela mudança de fase $\delta(\mathrm{k})$ pelo átomo absorvedor, uma vez que o fotoelétron "sente" o potencial criado por este átomo duas vezes. O decaimento da onda devido ao livre caminho médio ou tempo de vida finito (incluído o tempo de vida do buraco do caroço) do fotoelétron é expresso no termo $\mathrm{e}^{-2 \mathrm{R} i / \lambda(\mathrm{k})}$. Este fator é fortemente responsável pelo curto alcance (da ordem de $\AA$, onde $1 \AA=10-10 \mathrm{~m}$ ) no material sondado nos experimentos EXAFS. A força das ondas de interferência refletidas depende do tipo e do número de átomos vizinhos através da amplitude de retroespalhamento $f(k)$ que se reflete intensamente na magnitude do sinal EXAFS. O fator Debye-Waller inclui flutuações no comprimento da ligação devido à temperatura e a desordem estrutural. Outros fatores, como o fator de onda esférica $\left(\frac{1}{k R_{j}^{2}}\right)$ e o termo de livre caminho médio, são secundários, mas importantes para a análise quantitativa da amplitude EXAFS.

\section{Critérios gerais de análise de dados}

Existem critérios bem estabelecidos para a análise do espectro de EXAFS que são reportados em vários livros e artigos. Cada etapa do tratamento básico dos dados está ilustrada na Figura 7.

\section{(A) Isolando $\chi(k)$ dos dados experimentais}

Em um experimento de transmissão, $\mu(\mathrm{x})$ é obtido a partir das medidas de $\mathrm{I}_{0}$, intensidade da radiação antes da amostra, e $I_{t}$, intensidade da radiação após a amostra,

$$
\mu(x)=\ln \left(\frac{I_{0}}{I_{t}}\right)
$$
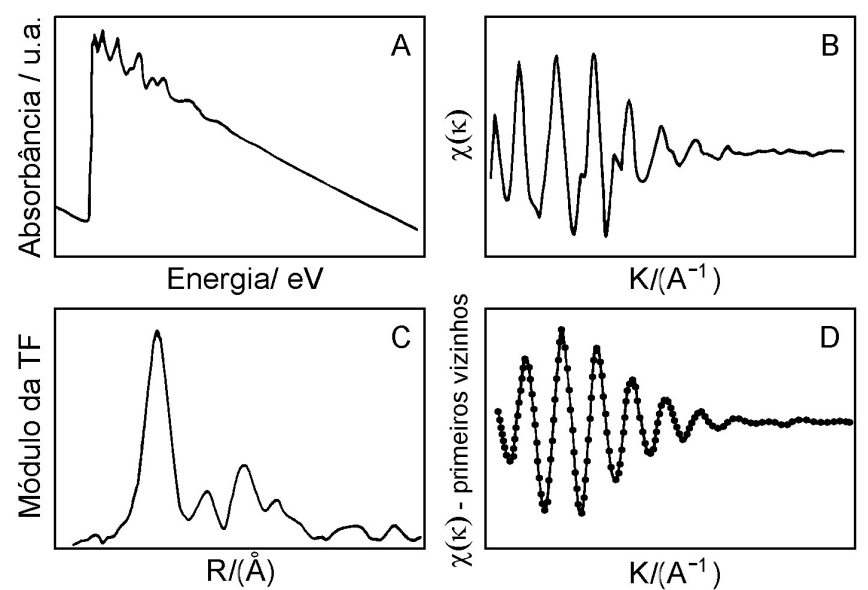

Figura 7 - Tratamento das oscilações EXAFS de amostra $\mathrm{Cu}_{90} \mathrm{Co}_{10}$. (A) espectro de absorção obtido; (B) sinal de EXAFS $\chi(\mathrm{k})$; (C) transformada de Fourier do sinal de EXAFS e (D) os pontos representam a transformada de Fourierinversa do primeiro pico do gráfico mostrado em C. A linha contínua é o ajuste da equação de

EXAFS, utilizando os parâmetros atômicos obtidos do padrão [14].

Como definido na equação $(7), \chi(\mathrm{E})$ pode ser obtido uma vez que a absorção atômica é conhecida pelo cálculo 


$$
\chi(E)=\frac{\mu_{\text {total }}-\mu_{\text {atômico }}}{\mu_{\text {atômico }}}
$$

Antes de $\mu_{0}$ ser determinada, a pré-borda (absorção de raios-X antes da borda de absorção) tem que ser subtraída. A pré-borda é normalmente aproximada por uma função Victoreen modificada [1] e calculada por extrapolação dos dados desta região.

Após a subtração da pré-borda, a energia da borda (isto é, $\mathrm{E}_{\text {edge }}$ ) deve ser definida. O valor da energia da borda é usado no cálculo de $\mathrm{k}\left(\AA^{-1}\right)$ como dado pela equação (5). A escolha desta energia é bastante arbitrária. O ponto de inflexão (isto é, o máximo na primeira derivada da borda de absorção) é geralmente considerado. Contudo, as presenças de excitações eletrônicas e ressonâncias podem encobrir a exata posição da $\mathrm{E}_{\text {edge }}$. A fim de se evitar esta complexidade, a posição a meia altura da borda normalizada é também freqüentemente escolhida como $\mathrm{E}_{\text {edge }}$. O potencial interno, $\mathrm{E}_{0}$, é normalmente escolhido como zero.

O background atômico $\left(\mu_{\text {atômico }}\right)$ após a borda de absorção é determinado normalmente utilizando uma função cubic spline [38].

Antes de $\chi(\mathrm{k})$ ser determinado, a absorção total obtida experimentalmente deve ser normalizada $50 \mathrm{eV}$ após a borda de absorção. Finalmente, $\chi(\mathrm{k})$ é calculado segundo a equação (11).

\section{(B) Transformada de Fourier}

A função $\chi(\mathrm{k})$ é uma somatória de vários termos seno de diferentes freqüências. A transformada de Fourier (TF) resolve o espalhamento de cada distância em uma banda fina de coeficiente de Fourier ao longo do eixo R, isto é, a transformada de Fourier de $\mathrm{k}^{\mathrm{n}} \chi(\mathrm{k})$ resulta em uma função de distribuição radial definida no espaço-R:

$$
T F(R)=\frac{1}{\sqrt{2 \pi}} \int_{k \min }^{k \max } w(k) k^{n} \chi(k) e^{i 2 k R} d k
$$

$\mathrm{Na}$ TF está incluída uma função “janela” w(k) (também denominada de função filtro) que seleciona o intervalo em k a ser transformado, determinante na resolução da transformada de Fourier. A TF pode ser obtida com diferentes pesos em $\mathrm{k}$ (multiplicada por uma potência $\mathrm{k}^{\mathrm{n}}$ ), o que ajuda a enfatizar as regiões de maior intensidade do espalhamento dos elementos ao redor do átomo absorvedor.

A transformada resultante é uma função complexa. A parte absoluta da TF é determinada principalmente pelo número de vizinhos e distorções, e a parte imaginária é bastante utilizada na análise da distância entre os átomos absorvedor-espalhador.

\section{(C) Filtragem da TF-Transformada inversa}

A filtragem da TF envolve a transformada de Fourier dos dados $\mathrm{k}^{\mathrm{n}} \chi(\mathrm{k})$ no espaço $\mathrm{R}$, selecionando o intervalo de distância de interesse (isolamento das esferas de coordenação) e a transformada inversa dos dados para o espaço k. Portanto, a função resultante $\chi_{i}(\mathrm{k})$ é para uma específica esfera. Este método permite obter padrões de amplitude do retroespalhamento e da fase a partir de compostos de referência.

\section{(D) Fase e amplitude do retroespalhamento derivadas do espectro EXAFS de composto padrão}

Para que na equação (8) seja determinado o número de coordenação, a distância e a desordem, a amplitude do retroespalhamento e a fase devem ser conhecidas. Os dois últimos parâmetros são transferíveis de um composto para outro, se o mesmo par absorvedor-espalhador esta envolvido e se a estrutura deste composto padrão é bem conhecida. O espectro de absorção de raios$\mathrm{X}$ é obtido para este padrão, e $\chi_{\mathrm{i}}(\mathrm{k})$ é isolado para uma esfera de coordenação segundo o procedimento descrito anteriormente, obtém-se então,

$$
\chi_{\text {ref }}(\mathrm{k})=\mathrm{A}_{\text {ref }}(\mathrm{k}) \operatorname{sen}\left[2 \mathrm{kR}_{\text {ref }}+2 \delta_{\text {cref }}(\mathrm{k})+\phi_{\text {ref }}\right]
$$

Afase $\left(2 \delta_{\text {cref }}(\mathrm{k})+\phi_{\text {ref }}(\mathrm{k})\right)$ e a amplitudedo retroespalhamento $\mathrm{f}_{\text {ref }}(\mathrm{k})$ podem ser determinados utilizando as funções $\mathrm{A}_{\text {ref }}(\mathrm{k})$ e $\left[2 \mathrm{kR}_{\text {ref }}+2 \delta_{\text {cref }}(\mathrm{k})+\phi_{\text {ref }}\right]$ e os valores conhecidos de $\mathrm{N}_{\text {ref }}$ e $\mathrm{R}_{\text {ref }}$ A hipótese da transferibilidade química da fase e da amplitude do retroespalhamento supõe que estes valores se conservem de um sistema a outro, sendo válida desde que as ligações químicas ou as distâncias não variem muito do sistema modelo para o sistema desconhecido.

A principal vantagem de utilizar os parâmetros experimentais é que se eles são analisados (além de obtidos) sob as mesmas condições das amostras desconhecidas, os fatores que de uma certa maneira são subjetivos, como a normalização, $\mathrm{E}_{0}$, subtração do background, efeitos multieletrônico e inelástico acabam sendo compensados. 


\section{Equipamentos}

Inicialmente, para se obter um espectro de EXAFS/ XANES utilizava-se o espectro contínuo de um tubo de raios-X [39]. Contudo, a técnica de EXAFS somente se tornou prática com o advento das fontes de radiação síncrotron, que além do espectro contínuo, possibilitaram um fluxo de fótons na amostra de pelo menos seis ordens de grandeza maior que a região do espectro branco das fontes de raios-X convencionais, como citado anteriormente [1213].

A Figura 8 mostra uma montagem experimental utilizada para obter os espectros de absorção de uma fonte síncrotron.

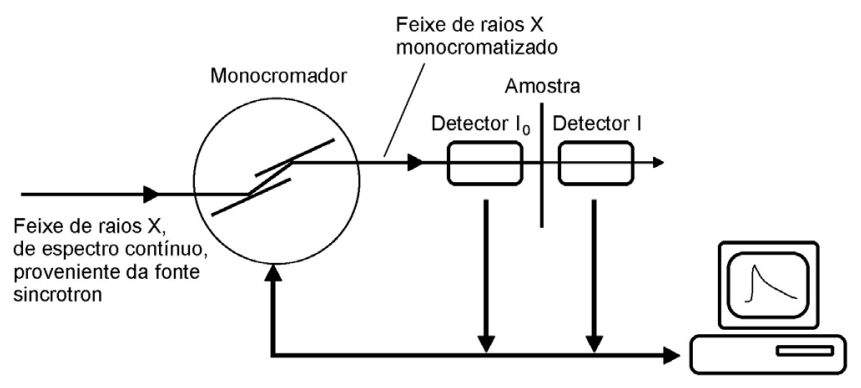

Figura 8 - Esquema da montagem experimental utilizada para a obtenção dos espectros de absorção [14].

Para a seleção da energia do feixe de raios-X utiliza-se um monocromador baseado na difração em cristais perfeitos, onde a seleção da energia é feita variando-se o ângulo de incidência do feixe sobre o cristal. A utilização da dupla reflexão do feixe de raios-X é a maneira mais comum para se obter uma melhor resolução em energia e manutenção da posição do feixe sobre a amostra. Um conjunto de fendas delimita o perfil do feixe proveniente da fonte síncrotron sobre o primeiro cristal do monocromador. Um segundo conjunto de fendas serve como fendas de guarda, evitando que o feixe espalhado alcance a amostra.

A forma mais comum de se obter um espectro de absorção é através da configuração chamada de transmissão, onde se monitora o feixe incidente na amostra e o feixe transmitido com o auxílio de detectores antes e após a amostra. Para tanto, a amostra deve ser suficientemente fina para proporcionar uma boa relação sinal/ruído na medida da intensidade do feixe transmitido. Espessuras típicas para materiais metálicos puros não passam de alguns centésimos de milímetro. No caso da espessura da amostra ultrapassar esse limite, ou nos casos em que a amostra é sustentada em um substrato (caso de filmes finos), outros métodos de detecção da fluorescência da amostra ou dos elétrons secundários gerados no processo de absorção são utilizados. Estes últimos métodos de detecção também são utilizados no casos em que o elemento químico a ser analisado está em pequena concentração na amostra.

A Figura 9 exibe a linha de absorção de raios-X do Laboratório Nacional de Luz Síncrotron (LNLS, Campinas - SP) [40].

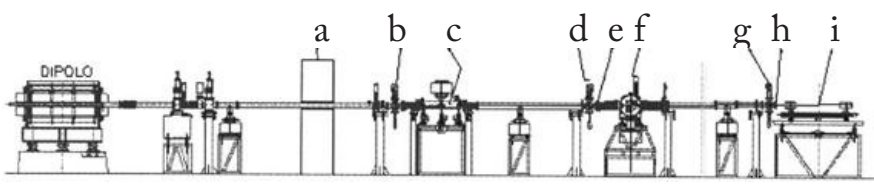

Figura 9 - Linha de absorção de raios-X (XAS) do LNLS - Campinas -SP. a) parede de proteção; b) fendas pré espelho; c) espelho; d) fendas pré monocromador; e) janela de berílio; f) monocromador; $g$ ) fendas pós monocromador; h) janela de Kapton ei) bancada experimental.

A fonte de luz do LNLS é um síncrotron de terceira geração constituído por um anel de armazenamento de elétrons de 29,7 m de diâmetro, com uma energia de operação de 1,37 $\mathrm{GeV}$; operando atualmente com uma corrente de elétrons (máximo) de $175 \mathrm{~mA}$ e tempo de vida do feixe de elétrons da ordem de 15 horas. A radiação provém de um dos doze dipolos do anel de armazenamento. Antes da parede de proteção radiológica existe o sistema de front-end, que protege $o$ anel de armazenamento contra possíveis falhas na linha de luz. Após a parede de proteção radiológica existe um conjunto de máscaras e fendas que delimitam o perfil do feixe, que em seguida passa por um espelho, cuja função é focalizar verticalmente e reduzir a intensidade da região de mais alta energia do espectro contínuo proveniente do dipolo. Antes de alcançar o monocromador o feixe é novamente definido por um conjunto de fendas. $O$ feixe atravessa a seguir um conjunto de fendas de guarda, que têm como objetivo impedir a passagem do feixe espalhado. Todo esse sistema opera sob alto vácuo ( $\left.10^{-8} \mathrm{~Pa}\right)$, sendo isolado do ultra alto vácuo $\left(\sim 10^{-11} \mathrm{~Pa}\right)$ do anel por uma janela de berílio e da pressão atmosférica na bancada experimental por uma janela de Kapton ${ }^{22}$, após a qual o feixe está pronto para ser utilizado.

\section{Aplicações das técnicas: XPS e XAS}

As técnicas de XPS e XAS têm sido utilizadas na caracterização de diversos materiais, como óxidos mistos [41-44], cerâmicas [45, 46], catalisadores [47-51], semicondutores [52-54], entre outros. Alguns exemplos são apresentados a seguir envolvendo as aplicações dessas técnicas na caracterização de sólidos inorgânicos.

Leroux e colaboradores [55] sintetizaram e caracterizaram 
óxidos mistos amorfos $\mathrm{MnV}_{2} \mathrm{O}_{6+\delta} \cdot n \mathrm{nH}_{2} \mathrm{O}(0<\delta<1)$, sendo que XPS e EXAFS foram duas das técnicas que utilizaram na investigação estrutural desse material. Foram obtidos os espectros de XPS correspondentes aos níveis de energia 1 s do $\mathrm{O}, 1$ s, 2 p e $3 p$ do $M n$ e $2 p$, 3 s e $3 p$ do $V$ e os espectros de EXAFS e XANES da borda $\mathrm{K}$ do vanádio e do mangânes do óxido $\mathrm{MnV}_{2} \mathrm{O}_{6,96}, 1,7 \mathrm{H} 2 \mathrm{O}$. Como padrão para as análises foram selecionados os próprios precursores da amostra, os compostos $\mathrm{MnV}_{2} \mathrm{O}_{6} \cdot 4 \mathrm{H}_{2} \mathrm{O}$ e $\mathrm{MnV}_{2} \mathrm{O}_{6}$.

Os espectros de XPS são mostrados na Figura 10.
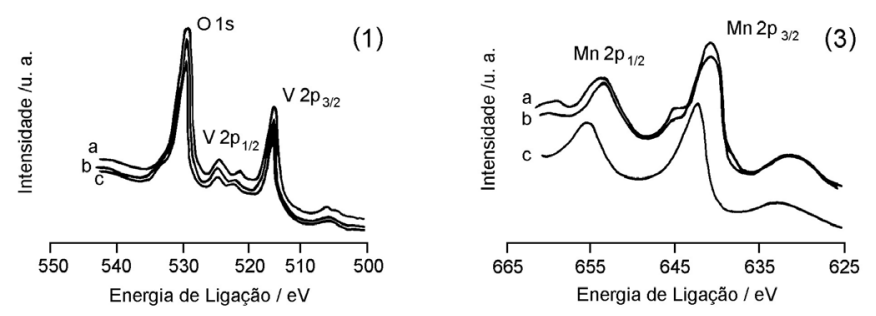

(2)
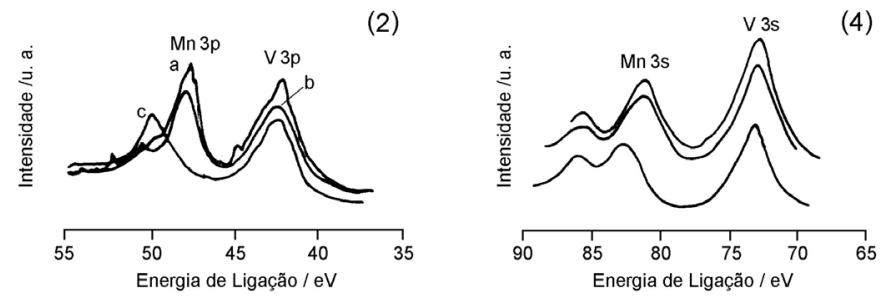

Figura 10 - Espectros de XPS do O 1s, Mn 1s, 2p e 3p e V2p, 3 e $3 p$ dos óxidos (a) $\mathrm{MNV}_{2} \mathrm{O}_{6} \cdot 4 \mathrm{H}_{2} \mathrm{O}$; (b) $\mathrm{MnV}_{2} \mathrm{O}_{6}$ e (c) $\mathrm{MNV}_{2} \mathrm{O}_{6,96} \cdot 1,7 \mathrm{H}_{2} \mathrm{O}[55]$.

Os picos fotoelétricos referentes aos níveis $2 \mathrm{p}, 3 \mathrm{p}$ e $3 \mathrm{~s}$ do vanádio da amostra $\mathrm{MnV}_{2} \mathrm{O}_{6.96} \cdot 1,7 \mathrm{H}_{2} \mathrm{O}$ apresentaram as mesmas energias em relação aos padrões, mostrando que o vanádio encontra-se no estado de oxidação +5 . Por outro lado, todos os picos do manganês encontramse deslocados para maiores valores de energia quando comparados aos valores dos padrões devido a diferença no estado químico. A energia de ligação do nível $3 p$ do Mn é sensível tanto ao ambiente quanto ao estado de oxidação, o que claramente confirma um aumento do estado de oxidação, pois o valor de $50 \mathrm{eV}$ para o nível $3 \mathrm{p}$ do $\mathrm{Mn}$ do composto $\mathrm{MnV}_{2} \mathrm{O}_{6.96} \cdot 1,7 \mathrm{H} 2 \mathrm{O}$ observado é atribuído ao $\mathrm{Mn}^{4+}$ em uma coordenação octaédrica ${ }^{23}$. Segundo os pesquisadores, o aumento do estado de oxidação do Mn é devido a etapa de ozonização do processo de preparação das amostras.

$\mathrm{Na}$ Figura 11 estão apresentados os módulos das TF dos espectros EXAFS da borda $\mathrm{K}$ do vanádio. Como pode ser observado, a coordenação do vanádio na amostra $\mathrm{MnV}_{2} \mathrm{O}_{6.96} \cdot 1,7 \mathrm{H}_{2} \mathrm{O}$ é diferente da coordenação encontrada no padrão $\mathrm{NH}_{4} \mathrm{VO}_{3}$. $\mathrm{O} \mathrm{NH}_{4} \mathrm{VO}_{3}$ apresenta duas distâncias interatômicas (1,66 e 1,81 A) para a ligação $\mathrm{V}-\mathrm{O}$ (primeira esfera de coordenação), enquanto que a amostra $\mathrm{MnV}_{2} \mathrm{O}_{6.96} \cdot 1,7 \mathrm{H}_{2} \mathrm{O}$ três distâncias (1,65; 1,90 e $2,06 \AA$ ).

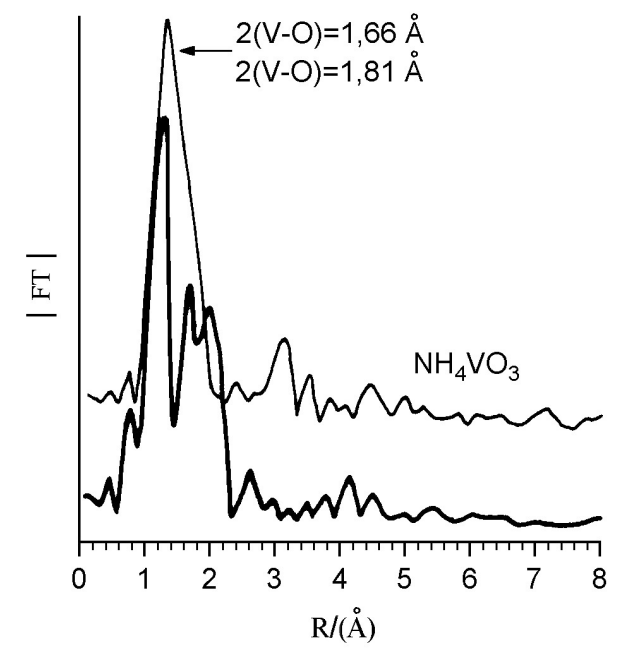

Figura 11 - Módulos das TF dos espectros EXAFS da borda K do V dos óxidos $\mathrm{NH}_{4} \mathrm{VO}_{3}$ e $\mathrm{MnV}_{2} \mathrm{O}_{6,96}[55]$.

Estes valores estão próximos aos encontrados para o precursor $\mathrm{MnV}_{2} \mathrm{O}_{6} \cdot 4 \mathrm{H}_{2} \mathrm{O}$ com um número de vizinhos próximo de 5 (TF não mostrada). Os autores concluíram que a etapa de ozonização não muda o arranjo da primeira camada próxima ao átomo de vanádio.

A Figura 12 mostra os módulos das TF dos espectros EXAFS da borda $\mathrm{K}$ do manganês.

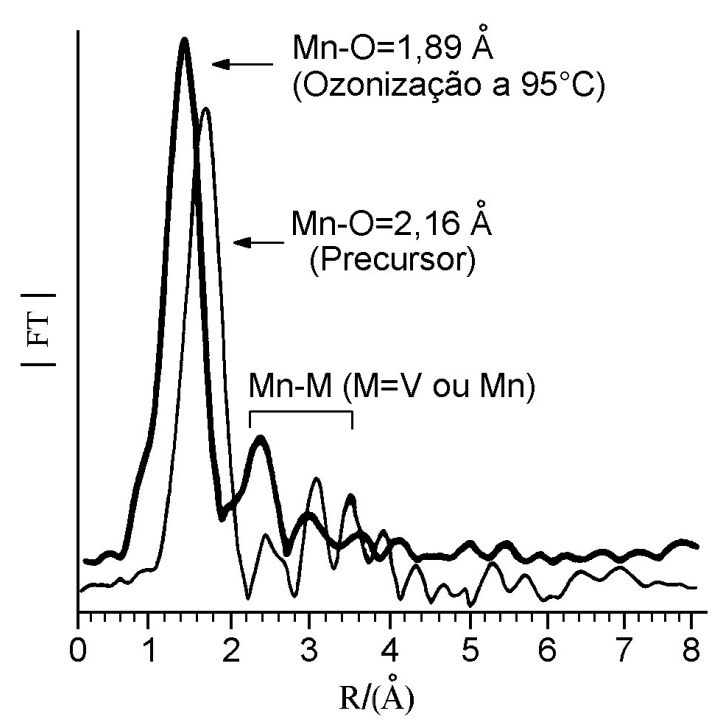

Figura 12 - Módulos das TF do espectro EXAFS da borda K do Mn dos óxidos $\mathrm{MnV}_{2} \mathrm{O}_{6} \cdot 4 \mathrm{H}_{2} \mathrm{O}$ e $\mathrm{MnV}_{2} \mathrm{O}_{6,96} \cdot 1,7 \mathrm{H}_{2} \mathrm{O}$ [55].

A comparação entre as $\mathrm{TF}$ dos compostos $\mathrm{MnV}_{2} \mathrm{O}_{6.96}$ e $\mathrm{MnV}_{2} \mathrm{O}_{6} \cdot 4 \mathrm{H}_{2} \mathrm{O}$ mostra uma mudança na distância interatômica da ligação $\mathrm{Mn}-\mathrm{O}$ para $1,895 \AA$ (2,16 ̊̊ no precursor), o que estaria de acordo com o manganês no 
estado de oxidação +4 e coordenação igual a 6. Porém, a simulação computacional do número de vizinhos calculado através dos dados do espectro EXAFS teve como resultado 4,2. Levando-se em consideração os erros na determinação deste número e as características da pré-borda do espectro XANES (não mostrado), os pesquisadores concluíram que o número de primeiros vizinhos para o átomo de manganês é 6 .

As técnicas de XPS e EXAFS possibilitaram determinar os estados de oxidação, número de coordenação, distâncias interatômicas e os números de vizinhos em relação aos átomos estudados. É importante salientar que os padrões utilizados na caracterização dos materiais devem ser adequados.

Meng e colaboradores [56] reportaram resultados da caracterização, entre outras XAS e XPS, e da performance catalítica de uma série de catalisadores $\mathrm{Co}-\mathrm{Pt}(\mathrm{Pd}, \mathrm{Rh}) / \gamma$ $\mathrm{Al}_{2} \mathrm{O}_{3}$ e $\mathrm{Co} / \gamma-\mathrm{Al}_{2} \mathrm{O}_{3}$ empregados na oxidação de $\mathrm{CO}$, decomposição de $\mathrm{NO}$ e redução catalítica seletiva de $\mathrm{NO}$ por $\mathrm{C}_{2} \mathrm{H}_{4}$.

O espectro de XPS do Co $2 \mathrm{p}_{3 / 2}$ do catalisador $\mathrm{Co} / \gamma-\mathrm{Al}_{2} \mathrm{O}_{3}$ é apresentado na Figura 13a.

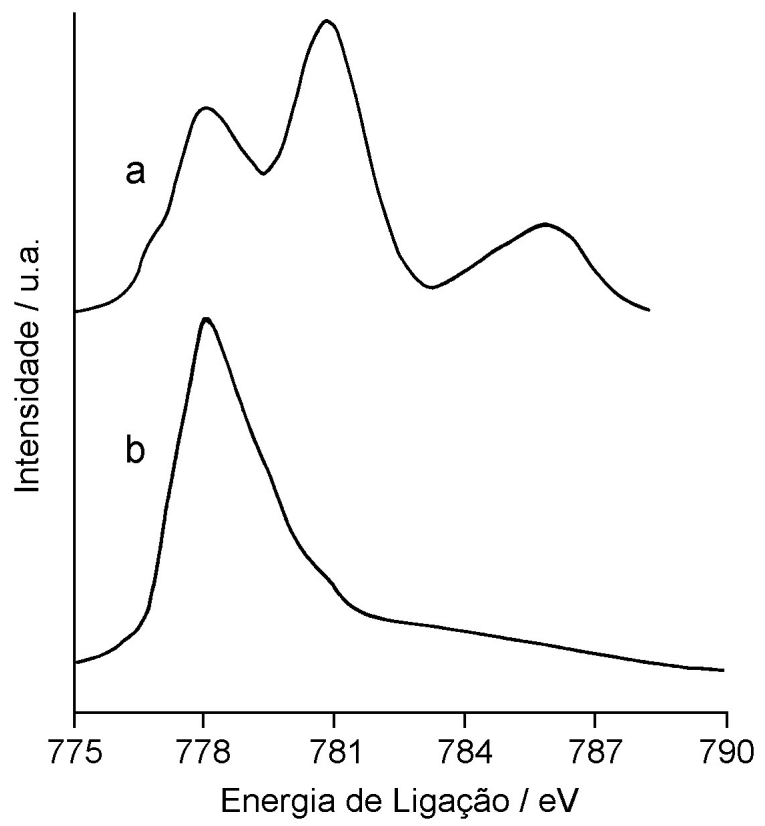

Figura 13 - Espectros de XPS do Co $2 \mathrm{p}_{3 / 2}$ das amostras $\mathrm{Co} / \gamma-\mathrm{Al}_{2} \mathrm{O}_{3}$ (a) e Co-Pt $/ \gamma-\mathrm{Al}_{2} \mathrm{O}_{3}$ (b) [56].

Dois picos a baixa energia de ligação são observados $(778,3$ e 780,9 eV). A energia de ligação do primeiro e do segundo picos são bastante próximas as energias do Co metálico e do $\mathrm{CoAl}_{2} \mathrm{O}_{4}$, respectivamente. Um pico satélite bastante largo típico para $\mathrm{Co}^{2+}$ é visto em 786,0 eV. Já para o $\mathrm{Co}-\mathrm{Pt}(\mathrm{Pd}, \mathrm{Rh}) / \gamma-\mathrm{Al}_{2} \mathrm{O}_{3}$ apenas um pico em $778,3 \mathrm{eV}$ é observado (Figura 13b). Estes resultados sugerem que o cobalto sobre a superfície do material $\mathrm{Co} / \gamma-\mathrm{Al}_{2} \mathrm{O}_{3}$ existe nas formas de $\mathrm{Co}$ metálico e $\mathrm{CoAl}_{2} \mathrm{O}_{4}$, enquanto que na amostra $\mathrm{Co}-\mathrm{Pt}(\mathrm{Pd}, \mathrm{Rh}) / \gamma-\mathrm{Al}_{2} \mathrm{O}_{3}$ todo cobalto existe como Co metálico. Estes resultados corroboram com os dados de difração de raios-X.

Os módulos das TF dos espectros EXAFS da borda K do Co podem ser obtidos na Figura 14.

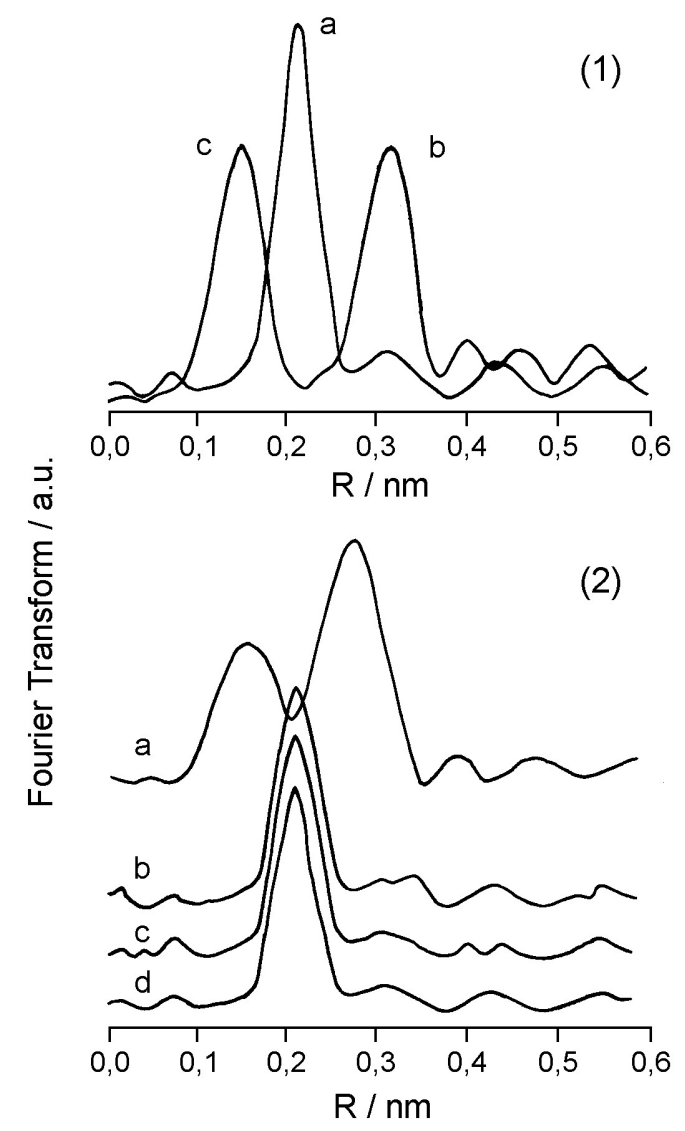

Figura 14 - Módulos da TF dos espectro EXAFS da borda K do Co das amostras (1) (a) Co metálico e (b) CoAl2O4; (2) (a) Co/ $\gamma-\mathrm{Al}_{2} \mathrm{O}_{3}$, (b) $\mathrm{Co}-\mathrm{Pt} / \gamma-\mathrm{Al}_{2} \mathrm{O}_{3}$, (c) $\mathrm{Co}-\mathrm{Pd} / \gamma-\mathrm{Al}_{2} \mathrm{O}_{3}$ e (d) $\mathrm{Co}-\mathrm{Rh} / \gamma-\mathrm{Al}_{2} \mathrm{O}_{3}[56]$.

A TF do $\mathrm{Co}-\mathrm{Pt}(\mathrm{Pd}, \mathrm{Rh}) / \gamma-\mathrm{Al}_{2} \mathrm{O}_{3}$ é similar ao do $\mathrm{Co}$ metálico, mostrando apenas uma camada de coordenação em 0,212 nm. Contudo, na TF do catalisador $\mathrm{Co} / \gamma-$ $\mathrm{Al}_{2} \mathrm{O}_{3}$ aparecem duas camadas de coordenação em 0,147 e $0,266 \mathrm{~nm}$, respectivamente. A primeira camada pode ser relacionada a camada $\mathrm{Co}-\mathrm{O}$ em $\mathrm{CoAl}_{2} \mathrm{O}_{4}(0,143 \mathrm{~nm})$, mas a segunda não pode ser considerada como $\mathrm{Co}-\mathrm{Co}$ em Co metálico $(0,212 \mathrm{~nm})$ ou Co-Co em $\mathrm{CoAl}_{2} \mathrm{O}_{4}(0,312$ $\mathrm{nm}$ ), pois a diferença de distância interatômica é muito grande. Com base nos dados de difração de raios-X e XPS, o autor sugere que a segunda camada apresenta uma contribuição de ambos Co metálico e $\mathrm{CoAl}_{2} \mathrm{O}_{3}$. Através dos cálculos computacionais dos parâmetros estruturais da esfera Co-Co obtidos a partir dos dados de EXAFS $\mathrm{da}$ borda $\mathrm{K}$ do cobalto inferiu-se que este elemento na 
amostra $\mathrm{Co}-\mathrm{Pt}(\mathrm{Pd}, \mathrm{Rh}) / \gamma-\mathrm{Al}_{2} \mathrm{O}_{3}$ existe na forma metálica e na amostra $\mathrm{Co} / \gamma-\mathrm{Al}_{2} \mathrm{O}_{3}$ como uma mistura de $\mathrm{Co}$ metálico e $\mathrm{CoAl}_{2} \mathrm{O}_{4}$ do tipo espinélio ${ }^{24}$.

As técnicas nesse caso foram importantes para associar o estado de oxidação do cobalto presente sobre as matrizes dos catalisadores com as diferentes fases cataliticamente ativas presentes nos catalisadores $\mathrm{Co}-\mathrm{Pt}(\mathrm{Pd}, \mathrm{Rh}) / \gamma-\mathrm{Al}_{2} \mathrm{O}_{3}$ $\mathrm{e} \mathrm{Co} / \gamma-\mathrm{Al}_{2} \mathrm{O}_{3}$.

Gonçalves e colaboradores [57] obtiveram os óxidos mistos $\mathrm{SiO}_{2} / \mathrm{TiO}_{2}$ e $\mathrm{SiO}_{2} / \mathrm{TiO}_{2} / \mathrm{Sb}_{2} \mathrm{O}_{3}$ através do processo gel para diferentes teores de $\mathrm{Ti}$ e $\mathrm{Sb}$ nas matrizes. Estes materiais tiveram suas estruturas caracterizadas através das técnicas de XPS e XAS na borda K do titânio.

A Figura 15 exibe o espectro de XPS para o Ti $2 \mathrm{p}$ e $\mathrm{Sb}$ $3 \mathrm{~d}_{3 / 2}$ e O $1 \mathrm{~s}$.

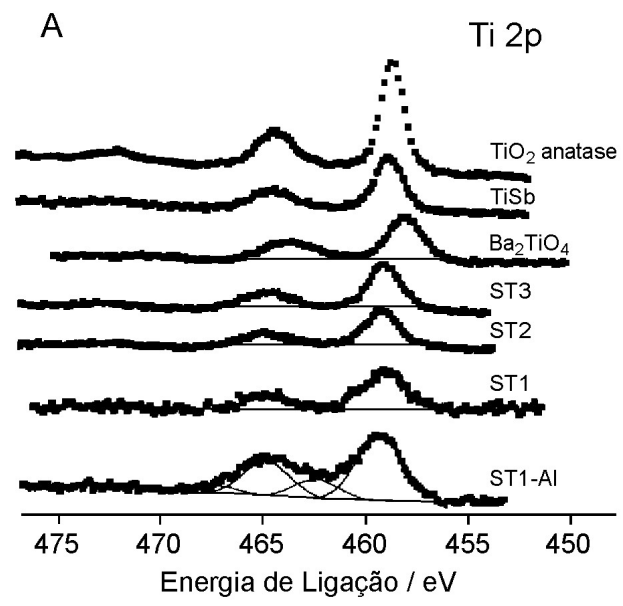

B

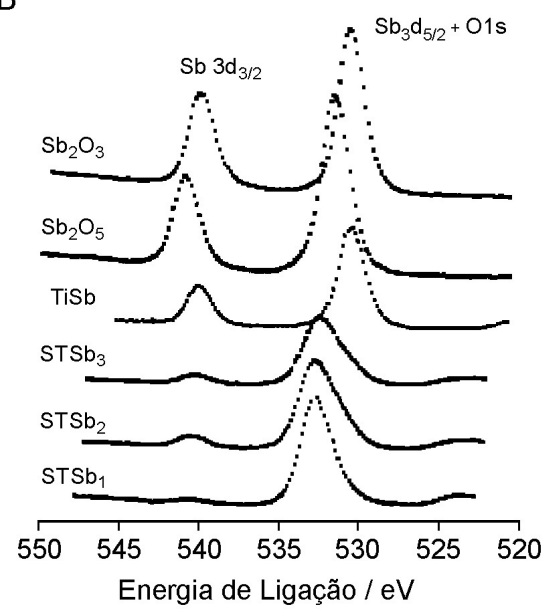

Figura 15 - Espectros de XPS do Ti 2p, Sb 3d e O 1s das amostras (A) ST1-A1 (excitado com ânodo de alumínio) e ST1, ST2, ST3, $\beta-\mathrm{Ba}_{2} \mathrm{TiO}_{4} \mathrm{e} \mathrm{TiO}_{2}$ anatase excitados com ânodo de magnésio; (B) STSB1, STSB2, STSB3, TiSb, $\mathrm{Sb}_{2} \mathrm{O}_{3}$ e $\mathrm{Sb}_{2} \mathrm{O}_{5}$ (excitado com ânodo de magnésio) [57].

Como pode ser observado na Figura 15A, quando a amostra é excitada pela linha $\mathrm{K} \alpha$ do $\mathrm{Al}$, o espectro $2 \mathrm{p}$ do titânio apresenta dois picos largos com energia de ligação localizados em 462,0 e 459,0 eV, que correspondem a componente spin-órbita $2 \mathrm{p}_{3 / 2}$. O pico centrado em 459,0 $\mathrm{eV}$ é observado em todos os casos. Quando os óxidos são excitados pela linha $\mathrm{K} \alpha$ do $\mathrm{Mg}$, os espectros dos óxidos apresentam somente o segundo pico $2 \mathrm{p}_{3 / 2}(459,0 \mathrm{eV})$, que é compatível com o estado de oxidação +4 em ambiente octaédrico. Os autores observaram que o pico em 462,0 $\mathrm{eV}$, formalmente atribuído ao $\mathrm{Ti}^{+4} \mathrm{em}$ ambiente tetraédrico no $\mathrm{TiO}_{2}$, deve-se ao $\mathrm{O} 1$ s da sílica excitado pela fonte $\mathrm{K} \beta$ do Al (1556,3 eV) com uma energia de ligação igual a energia do $\mathrm{O} 1 \mathrm{~s}$ em $532,5 \mathrm{eV}$ menos a diferença $\mathrm{Al}(\mathrm{K} \beta)$ $-\mathrm{Al}(\mathrm{K} \beta)=69,7 \mathrm{eV}$.

Os espectros de XPS do nível 3d do antimônio e 1s do oxigênio estão mostrados na Figura 15B. A análise do nível $3 \mathrm{~d}_{3 / 2}$ do antimônio revela a presença de somente um pico em 540,5 eV, o mesmo observado para a fase $\mathrm{Sb}_{2} \mathrm{O}_{5}$ $(540,5 \mathrm{eV})$. Portanto, nenhuma mudança em relação a energia de ligação para o titânio é observada com a incorporação de antimônio.

A análise dos módulos das TF dos espectros EXAFS (Figura 16) mostrou que o ambiente ao redor do titânio é o mesmo em todas as amostras.

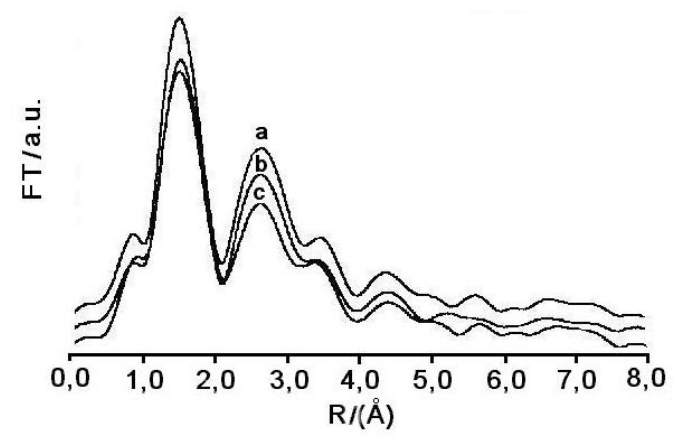

Figura 16 - Módulos das TF dos espectros de EXAFS da borda K do Ti das amostras (a) STC3, (b) STCSb3 e (c) $\mathrm{TiO}_{2}$ anatase [57].

Todos os óxidos apresentaram uma estrutura local ao redor do titânio igual a da fase cristalina anatase ${ }^{25}$, como pode ser observado comparando-se as transformadas de Fourier das amostras e do padrão. A presença da forma $\mathrm{TiO}_{2}$ anatase também foi verificada pela análise das características da pré-borda do espectro XANES.

As técnicas utilizadas mostraram que os átomos de titânio estão em sítios octaédricos na forma de $\mathrm{TiO}_{2}$ anatase. A possibilidade dos átomos de titânio estarem em ambiente tetraédrico foi descartada através dos resultados obtidos por XPS usando a linha Ka do magnésio, a qual mostra que a utilização da linha (linha $K \alpha$ do alumínio ou magnésio) não é adequada para a análise, podendo gerar 
interpretações erradas. Os autores utilizaram vários padrões, o que possibilitou a correta caracterização dos materiais.

Fernández e colaboradores [58] estudaram in situ a redução fotocatalítica (com uma lâmpada de mercúrio, $125 \mathrm{~W}$ ) de ouro sobre partículas coloidais de $\mathrm{TiO}_{2}$ na presença de i-PrOH por EXAFS. Os espectros de EXAFS da borda $\mathrm{L}_{\text {III }}$ do $\mathrm{Au}$ foram registrados para diferentes tempos de exposição de luz sobre a amostra, acompanhando a redução fotocatalítica de $\mathrm{Au}^{3+}$ em solução coloidal etanólica.

A Figura 17 exibe os módulos das TF das oscilações EXAFS obtidas em diferentes tempos de iluminação e de uma folha de ouro, utilizada como padrão.

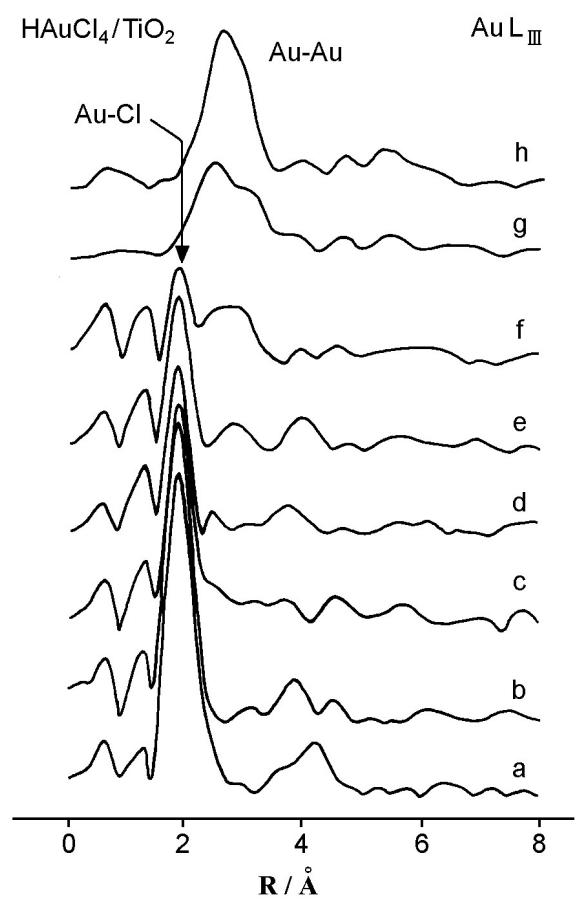

Figura 17 - Módulos das TF dos espectros EXAFS da borda $\mathrm{L}_{\mathrm{III}}$ do Au obtidos após diferentes tempos de iluminação durante a redução fotocatalítica de $\mathrm{Au}^{3+}$ sobre $\mathrm{TiO}_{2}$ coloidal. (a) $\mathrm{HAuCl}_{4}$, (b) 46 min, (c) $88 \mathrm{~min}$, (d) $120 \mathrm{~min}$, (e) $154 \mathrm{~min}$, (f) $183 \mathrm{~min}$, (g) $251 \mathrm{~min}$ e (h) follha de ouro [58].

O primeiro pico da $\mathrm{TF}$ corresponde a distância interatômica $\mathrm{Au}-\mathrm{Cl}$ para os ânions $\mathrm{AuCl}_{4}^{-}$inicialmente presentes na solução antes da irradiação, enquanto que o segundo pico corresponde a distância para $\mathrm{Au}-\mathrm{Au}$ na primeira camada de coordenação do ouro metálico. A distância de 2,28 Å para $\mathrm{Au}-\mathrm{Cl}$ apresenta um número de coordenação inicial igual a 4, correspondente as espécies puras $\left(\mathrm{AuCl}_{4}\right)^{-}$. Conforme se procede a fotorredução, o número de ligações $\mathrm{Au}-\mathrm{Cl}$ progressivamente decresce até zero quando a redução total ocorre. A presença da distância interatômica $\mathrm{Au}-\mathrm{Au}$ é observada somente para um período de 154 minutos.

Através de simulações computacionais foi observado que para períodos longos de irradiação o número de coordenação (distância de 2,87 Å) aumenta para um valor final igual a 12 , correspondente ao bulk (volume) encontrado em partículas grandes de ouro. Na realidade, quando pequenos aglomerados metálicos são examinados por EXAFS, o número de coordenação médio é menor que o observado no bulk do metal, uma vez que ocorre uma alta proporção de átomos superficiais (alta dispersão do metal). Essas partículas progressivamente aumentam sob iluminação até formar cristalitos com número completo de coordenação do ouro.

Estudos complementares de XPS foram realizados para comparar o mecanismo de crescimento durante a formação de cristalitos de ouro (espectros não mostrados). A análise mostra que a espécie $\mathrm{Au}^{+}$se fotorreduz em $\mathrm{Au}$ metálico imediatamente sobre iluminação. Os resultados também foram confirmados através de análise quantitativa do espectro de XPS, onde se observou decréscimo do pico fotoelétrico 4f $\left(\mathrm{Au}^{3+}\right)$ confirmando a aglomeração do metal em grandes partículas. O mesmo foi reduzido quando iluminado por 45 minutos.

De uma maneira geral, as técnicas permitiram acompanhar in situ a formação de cristalitos de ouro sobre as partículas coloidais de $\mathrm{TiO}_{2}$.

Nos últimos anos, os silicalitos de titânio apresentamse como uma das áreas de alto desenvolvimento da ciência de zeolitas $^{26}$. Eles combinam as vantagens de alta habilidade de coordenação de íons titânio (IV) com a hidrofobicidade da estrutura do silicalito, seletividade espacial, e geometria local específica dos sítios ativos [59]. $\mathrm{O}$ estudo de coordenação e a distribuição da esfera de simetria de coordenação de íons titânio estão discutidos em termos das técnicas XPS e EXAFS.

A Figura 18 mostra os espectros de XPS dos silicalitos de titânio em diferentes teores de titânio, zeolitas TS-1 (9,1\% de titânio), TS-2 (18,0\% de titânio), e (Al, Ti)-beta [60].
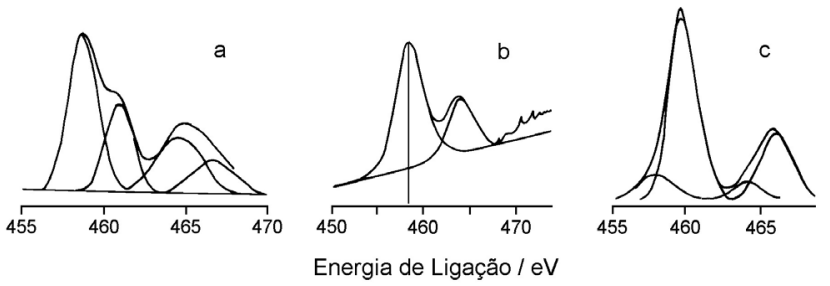

Figura 18 - Espectros deXPS do Ti2p para os silicalitos de titânio. (a) TS-1; (b) TS-2; (c) (A1, Ti)-beta [60]. 
Nos espectros das amostras TS-1 e (A1, Ti)-beta (Figuras 18a e 18c), observam-se dois picos na posição de máximo de energia de ligação em 458,3 e 460,6 eV. O primeiro pico de $\operatorname{Ti}\left(2 \mathrm{p}_{3 / 2}\right)$ de energia de ligação igual a 458,3 eV refere-se ao titânio coordenado a sítios octaédricos. A segunda contribuição em mais alta energia de ligação (460 $\mathrm{eV}$ ) é devido a compostos que apresentam uma pequena proporção de titânio em sítios tetraédricos, a amostra TS2 (Figura 18b).

No espectro da zeolita Ti-beta, preparado à partir da zeolita Al-beta, estão presentes os picos de $\operatorname{Ti}\left(2 \mathrm{p}_{3 / 2}\right) \mathrm{com}$ energias de ligação em 458,0 e 460,0 eV. Para este caso, a contribuição tetraédrica é maior, mas uma pequena contribuição de íons coordenados octaedricamente ocorre [61].

Francisco e colaboradores [62] prepararam catalisadores de cobre suportados por matriz de $\mathrm{TiO}_{2}$ modificada por $\mathrm{CeO}_{2}$ pelo método sol-gel, e estes catalisadores foram testados cataliticamente frente à reação de oxidação do metanol. Dentre as técnicas empregadas nas análises estão as de XAS e XPS. A principal conclusão dos pesquisadores é que uma fina camada de cério é formada sobre o $\mathrm{TiO}_{2}$, numa estrutura $\mathrm{Ce}-\mathrm{O}-\mathrm{Ti}$, na qual o cério teve seu ambiente local distorcido e uma segunda espécie de $\mathrm{Ti}(\mathrm{IV})$ foi originada na superfície. Nesta situação, as espécies de cobre estão bem dispersas sobre este suporte misto e o catalisador apresentou uma boa conversão do metanol, evidenciando o efeito sinérgico entre $\mathrm{CuO}$ e o suporte misto $\mathrm{CeO}_{2}-\mathrm{TiO}_{2}$ [63].

A distorção do ambiente local ao redor do cério pode ser observado através do espectro XANES da borda LIII do cério, e estes espectros estão mostrados na Figura 19.

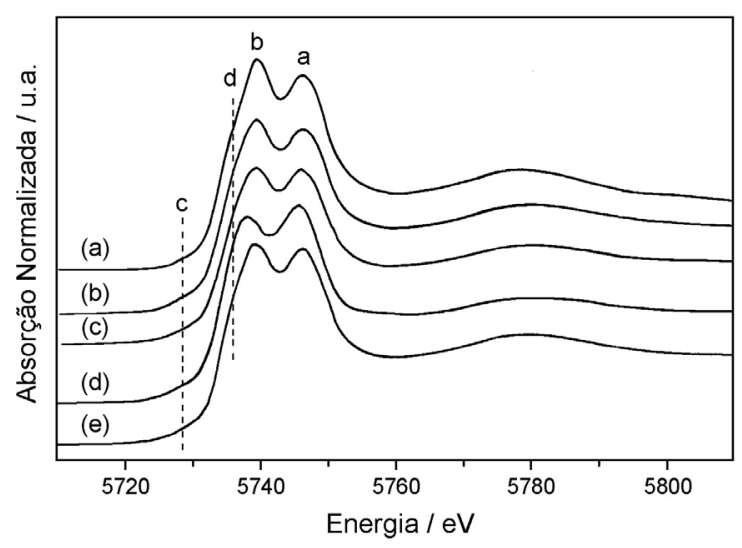

Figura 19 - Espectros XANES da borda LIII do CeXANES da referência e dos catalisadores, referencias: (a) $\mathrm{CeO}_{2}$ referência,

(b) $\mathrm{Ce}_{0,91} \mathrm{O}_{1,91} \mathrm{Cu}_{0,09}$, catalisadores, (c) $\mathrm{Ce}_{0,27} \mathrm{Ti}_{0,64} \mathrm{O}_{1,91} \mathrm{Cu}_{0,09}$, (d) $\mathrm{Ce}_{0,09} \mathrm{Ti}_{0,82} \mathrm{O}_{1,91} \mathrm{Cu}_{0,09}$ e (e) $\mathrm{Ce}_{0,41} \mathrm{Ti}_{0,41} \mathrm{O}_{1,82} \mathrm{Cu}_{0,18}$ [62].
Os picos denominados a, b e c são encontrados nos espectros de $\mathrm{Ce}(\mathrm{IV})$. $\mathrm{O}$ pico a é devido à transição $2 \mathrm{p}_{3 / 2}$ $\rightarrow\left(4 \mathrm{f}^{0}\right) 5 \mathrm{~d}$, enquanto que o pico b corresponde à transição de $2 \mathrm{p}_{3 / 2} \rightarrow\left(4 \mathrm{f}^{1} \underline{\mathrm{L}}\right) 5 \mathrm{~d}$ onde um elétron é transferido do orbital ligante $\underline{L}$ (isto é, $2 \mathrm{p}$ do oxigênio) para a camada $4 \mathrm{f}$ do cério. $\mathrm{O}$ pico c é assinalado à transição $2 \mathrm{p}_{3 / 2} \rightarrow 4 \mathrm{f}$ , que é proibida pela regra de seleção, $\Delta 1= \pm 1$, onde $\Delta 1$ é a variação do momento magnético orbital do elétron. A hibridização dos orbitais $5 \mathrm{~d}-4 \mathrm{f}$ permite a transição como um pequeno pico. A posição e a área do pico b relativa ao pico a dependem do ambiente químico do átomo de cério. $\mathrm{O}$ espectro do $\mathrm{Ce}(\mathrm{III})$ apresenta somente um único pico, denominado d, originado da transição $2 \mathrm{p}_{3 / 2} \rightarrow\left(4 \mathrm{f}^{1}\right) 5 \mathrm{~d}$.

Nos espectros XANES da referência $\mathrm{CeO}_{2}$ (Figura 19a), os picos principais a e b podem ser observados e estão separados por aproximadamente $7 \mathrm{eV}$. Estas duas componentes também aparecem nos espectros dos catalisadores com razão da intensidade e posição de energia próximas aos valores encontrados para a referência, exceto pelo catalisador $\mathrm{Ce}_{0,09} \mathrm{Ti}_{0,82} \mathrm{O}_{1,91} \mathrm{Cu}_{0,09}$. Uma vez que o pico denominado $\mathrm{c}$, referente à presença da espécie $\mathrm{Ce}(\mathrm{III})$, não aparece nos espectros das amostras, concluiu-se que os átomos de cério estão em um complexo tetravalente.

No espectro XANES do catalisador $\mathrm{Ce}_{0,09} \mathrm{Ti}_{0,82} \mathrm{O}_{1,91} \mathrm{Cu}_{0,09}$ (Figura 19d), a distância entre os picos principais a e b e suas intensidades relativas mostraram-se diferentes dos valores obtidos para os demais. $\mathrm{O}$ pico $\mathrm{b}$ neste catalisador está posicionado a um menor valor que nas outras amostras, ao passo que a intensidade do pico $b$ relativa ao pico a é menor, o que não ocorreu nos outros catalisadores. As dependências na posição e na intensidade relativa são causadas pela sensibilidade do pico b ao ambiente químico, e podem ser usadas como um indicador do caráter iônico/ covalente característico do orbital $5 \mathrm{f}$ do $\mathrm{Ce}(\mathrm{IV})$. Sendo assim, este catalisador teve sua distância $\mathrm{Ce}-\mathrm{O}$ (primeiro vizinho) distorcida das apresentadas pelo $\mathrm{CeO}_{2}$-referência e pelos outros catalisadores. Este resultado foi confirmado pelos espectros EXAFS da borda $\mathrm{L}_{\text {III }}$ do cério.

Os espectros EXAFS da borda $\mathrm{L}_{\text {III }}$ do cério dos catalisadores e do $\mathrm{CeO}_{2}$ estão mostrados na Figura 20.

Como podem ser observados, os espectros dos catalisadores $\mathrm{Ce}_{0,27} \mathrm{Ti}_{0,64} \mathrm{O}_{1,91} \mathrm{Cu}_{0,09}$ e $\mathrm{Ce}_{0,41} \mathrm{Ti}_{0,41} \mathrm{O}_{1,82} \mathrm{Cu}_{0,18}$ apresentam oscilações similares ao do espectro EXAFS do $\mathrm{CeO}_{2}$, enquanto que as do catalisador $\mathrm{Ce}_{0,09} \mathrm{Ti}_{0,82} \mathrm{O}_{1,91} \mathrm{Cu}_{0,09}$ são bastante diferentes. A fase e a amplitude utilizadas nas simulações computacionais dos espectros EXAFS foram obtidas da referência $\mathrm{CeO}_{2}$. Os catalisadores $\mathrm{Ce}_{0,27} \mathrm{Ti}_{0,64} \mathrm{O}_{1,91} \mathrm{Cu}_{0,09} \quad$ e $\quad \mathrm{Ce}_{0,41} \mathrm{Ti}_{0,41} \mathrm{O}_{1,82} \mathrm{Cu}_{0,18}$ apresentaram uma primeira esfera de coordenação 


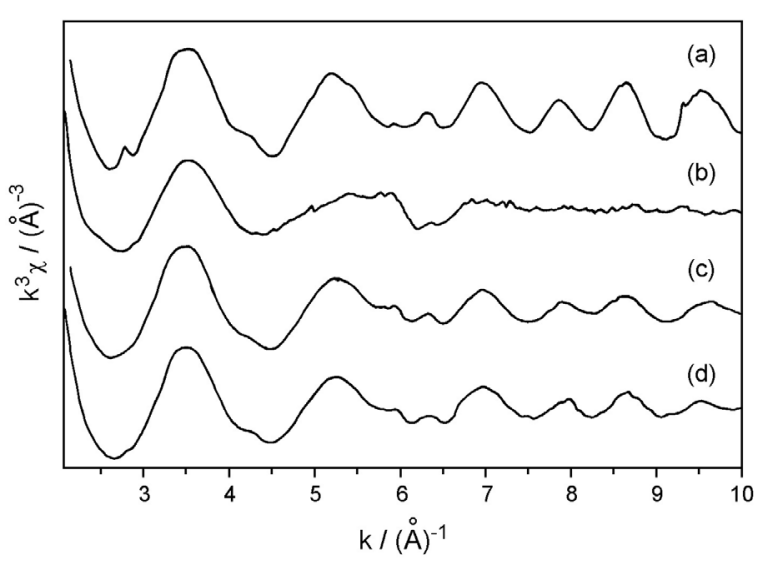

Figura 20 - Espectros EXAFS da borda $\mathrm{L}_{\mathrm{III}}$ da referência e dos catalisadores, (a) $\mathrm{CeO}_{2}$, (b) $\mathrm{Ce}_{0,09} \mathrm{Ti}_{0,82} \mathrm{O}_{1,91} \mathrm{Cu}_{0,09}$, (c) $\mathrm{Ce}_{0,27} \mathrm{Ti}_{0,64} \mathrm{O}_{1,91} \mathrm{Cu}_{0,09}$ e (d) $\mathrm{Ce}_{0,41} \mathrm{Ti}_{0,41} \mathrm{O}_{1,82} \mathrm{Cu}_{0,18}$ [62].

bastante similar à da referência, número de coordenação 8 e distância $\mathrm{Ce}-\mathrm{O}$ igual a $(2,30 \pm 0,03) \AA ̊$. Já para o catalisador $\mathrm{Ce}_{0.09} \mathrm{Ti}_{0,82} \mathrm{O}_{1,91} \mathrm{Cu}_{0,09}$ não foi possível simular os espectros EXAFS nas mesmas condições utilizadas nas simulações dos demais catalisadores. No entanto, uma boa simulação foi obtida levando-se em conta duas esferas de coordenação (6 átomos a $(2,25 \pm 0,02) \AA$ e 2 átomos a $(2,40 \pm 0,03) \AA$ ) para o espectro, sendo que o número médio de primeiros vizinhos foi igual a 8 e a distância média Ce-O 2,32 Å.

A Figura 21 mostra a evolução dos espectros de XPS obtidos para o nível $2 \mathrm{p}$ do $\mathrm{Ti}$ dos catalisadores conforme o acréscimo de cério, além do espectro das referências $\mathrm{Ti}_{0,91} \mathrm{O}_{1,91} \mathrm{Cu}_{0,09}$ e $\mathrm{TiO}_{2}$-anatase.

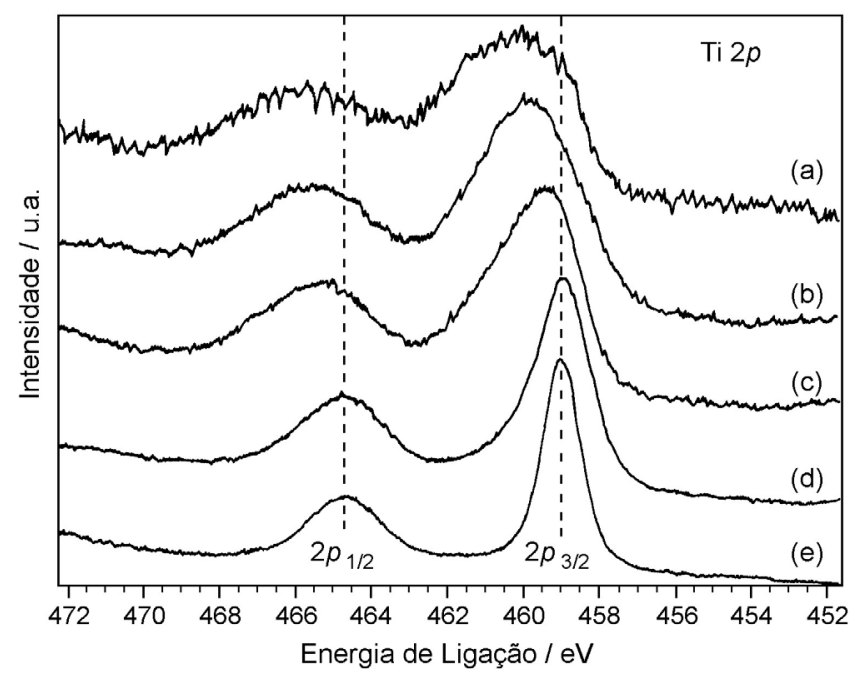

Figura 21 - Espectros de XPS do nível 2p do Ti dos catalisadores

(a) $\mathrm{Ce}_{0,45} \mathrm{Ti}_{0,46} \mathrm{O}_{1,91} \mathrm{Cu}_{0,09}$, (b) $\mathrm{Ce}_{0,27} \mathrm{Ti}_{0,64} \mathrm{O}_{1,91} \mathrm{Cu}_{0,09}$, (c)

$\mathrm{Ce}_{0,09} \mathrm{Ti}_{0,82} \mathrm{O}_{1,91} \mathrm{Cu}_{0,09}$ e das referências (d) $\mathrm{Ti}_{0,91}^{0,64} \mathrm{O}_{1,91} \mathrm{Cu}_{0,09}$ e (e) $\mathrm{TiO}_{2}$ -anatase [62].
$\mathrm{O}$ dubleto $2 \mathrm{p}$ do $\mathrm{Ti}$ do espectro da referência $\mathrm{TiO}_{2}$-anatase apresenta suas componentes spin-órbita em $459,0 \mathrm{eV}\left(2 \mathrm{p}_{3 / 2}\right)$ e 464,6 eV $\left(2 \mathrm{p}_{1 / 2}\right)$, as energias de ligação e a intensidade relativa (2:1). Para a referência $\mathrm{Ti}_{0,91} \mathrm{O}_{1,91} \mathrm{Cu}_{0,09}$, os picos $2 \mathrm{p}_{3 / 2}$ e $2 \mathrm{p}_{1 / 2}$ do espectro do titânio foram ajustados por picos únicos correspondentes ao $\mathrm{Ti}^{4+}$ em uma estrutura tetragonal.

Já os espectros dos catalisadores tiveram suas componentes melhor ajustadas por duas curvas para cada uma delas. Um conjunto dessas componentes foi atribuído ao titânio em um sítio tetragonal $\left(2 \mathrm{p}_{3 / 2}\right.$ em $459,2 \mathrm{eV}$ e $2 \mathrm{p}_{1 / 2}$ em $464,0 \mathrm{eV})$ e o segundo conjunto spin-órbita deslocado para maiores valores de energias ao titânio em uma simetria distorcida da espécie anterior $\left(2 \mathrm{p}_{3 / 2} \mathrm{em} 460,8 \mathrm{eV}\right.$ e $2 \mathrm{p}_{1 / 2}$ em 466,6 eV), ambas espécies com mesmo estado de oxidação. Analisando as áreas sob os picos $2 \mathrm{p}_{3 / 2}$ das duas espécies de $\mathrm{Ti}$, concluiu-se que o número de titânio superficial com número de oxidação igual a +4 , em uma estrutura diferente da espécie tetragonal é crescente com as sucessivas adições de cério ao suporte.

O fato da distorção da estrutura local do Ce ter sido detectada por XAS somente para o catalisador com $9 \%$ de $\mathrm{Ce}$ ocorreu porque para maiores concentrações deste elemento, a formação da fase cristalina $\mathrm{CeO}_{2}$ isolada em maior proporção (visível por difração de raios-X) impediu a deteç̧ão por XAS desta espécie de cério que interage com a superfície da titânia.

\section{Agradecimentos}

Os autores agradecem a Fundação de Amparo a Pesquisa do Estado de São Paulo (FAPESP) pelo auxílio financeiro. Ao S.L.P. Dias pela revisão do manuscrito.

\section{Referências}

1. Teo, B. K.; Joy, D. C., "EXAFS Spectroscopy: Techniques and Applications"; Plenum Press; New York, 1981.

2. Niemantsverdriet, J. W., "Spectroscopy in Catalysis: An Introduction", VCH Publishers, New York, 1995. 
3. Williams, D. B.; Carter, C.B., "Transmission Electron Microscopy: a Textbook for Materials Science”, vol.1, Plenum Press; New York and London, 1996.

4. Smith, G. C., "Surface Analysis by Electron Spectroscopy: Measurement and Interpretation"; Plenum Press; New York, 1994.

5. O'Connor, D. J.; Sexton, B. A.; Smart, R. St. C., "Surface Analysis Methods in Materiais Science"; Springer-Verlag; Berlin, 1992.

6. Walls, J. M., "Methods of Surface Analysis", Cambridge University Press; Cambridge, 1989.

7. Teo, B. K.; Lee, P. A., "Abinitio Calculations of Amplitude and Phase Functions for Extended XRay Absorption Fine-Structure Spectroscopy” Am. Chem. Soc. 1979, 101: 2815.

8. Teo, B. K.; Lee, P. A.; Simons, A. L.; Eisenberger, P.; Kincaid, B. M., "Exafs - Approximation, Parameterization, and Chemical Transferability of Amplitude Functions" J. Am. Chem. Soc. 1977, 99, 3854.

9. McKale, A. G.; Veal, B. W.; Paulikas, A. P.; Chan, S. K.; Knapp, G.S., "Improved Abinitio Calculations of Amplitude and Phase Functions for Extended XRay Absorption Fine-Structure Spectroscopy" J. Am. Chem. Soc. 1988, 110: 3763.

10. Woodruff, D. P.; Delchar, T. A., "Modern Techniques of Surface Science"; Cambridge University Press; Cambridge, 1986.

11. Ertl, G.; Küppers, J., "Low Energy Electrons and Surface Chemistry", VCH Publishers; Weinheim, 1985.

12. Kock, E.-E., "Handbook on Synchrotron Radiation"; North Holland Publishing Company; 1988.

13. Margaritondo, G., "Introduction to Synchroton Radiation”, Oxford University Press, Oxford, 1988.

14. Cezar, J. C., "Estudo por EXAFS de nanopartículas de cobalto imersas em uma matriz de cobre" Dissertação de Mestrado; UNICAMP, Campinas,
SP, 1998.

15. Clark, R.J.H., "Spectroscopy for Surface Science"; John Wiley \& Sons; Estados Unidos; 1998.

16. Seah, M. P.; Dench, W. A., "Quantitative Electron Spectroscopy of Surfaces: A Standard Data Base for Electron Inelastic Mean Free Paths in Solids" Surf. Interface Anal., 1979, 1: 2.

17. Nascente, P. A. P., "Análise de Superfícies por Espectroscopia de Elétrons” Rev. Bras. Aplic. Vácuo 1998, 17: 15.

18. Siegbahn, K., "ESCA: Atomic, Moleculcar and Solid State Structure Studied by Means of Electron Spectroscopy"; Almquist \& Wiksells; Uppsala, 1967.

19. Brundle, C. R.; Baker, A. D., "Electron Spectroscopy: Theory, Techniques and Applications"; Vols. 1-4; Academic Press; London, 1977-1981.

20. Lu, G; Bernasek, S.L.; Schwartz, J., "Oxidation of a Polycrystalline Titanium Surface by Oxygen and Water" Surf. Sci. 2000, 458: 80.

21. Moulder, J. F.; Stickle, W. F.; Sobol, P. E.; Bomben, K. D., "Handbook of X-ray Photoelectron Spectroscopy"; Chastain, J. (ed), Perkin-Elmer Corporation; Eden Prairie, 1992.

22. Chusuei, C. C.; Brookshier, M. A.; Goodman, D. W., "Correlation of Relative X-Ray Photoelectron Spectroscopy Shake-Up Intensity with $\mathrm{CuO}$ Particle Size" Langmuir 1999, 15: 2806.

23. Harrison, K.; Hazell, L. B., "The Determination of Uncertainties in Quantitative XPS AES and its Impact on Data Acquisition Strategy" Surf. Interface Anal. 1992, 18: 368.

24. Rehr,J.J.; Albers, R. C., "Theoretical Approaches to X-Ray Absorption Fine Structure” Rev. Mod. Phys. 2000, 72: 621 .

25. Larsson, P.-O.; Andersson, A., "Complete Oxidation of CO, Ethanol, and Ethyl Acetate Over Copper Oxide Supported on Titania and Ceria Modified Titania" J. Catal. 1998, 179: 72. 
26. Mullins, D.R.; Overbury, S.H.; Huntley, D. R., "Electron Spectroscopy of Single Crystal and Polycrystalline Cerium Oxide Surfaces” Surf. Sci. 1998, 409: 307.

27. Briggs, D.; Seah, M. P., "Practical Surface Analysis"; John Wiley \& Sons; Chichester, 1983.

28. O'Hanlon, J. F., "A User's Guide to Vacuum Technology”; John Wiley \& Sons; New York, 1989.

29. Musket, R. G.; McLean, W.; Colmenares, C. A.; Makowiecki, D. M.; Siekhaus, W. J., "Preparation of Atomically Clean Surfaces of Selected Elements - A Review” Appl. Surf. Sci. 1982, 10: 143.

30. De Siervo, A., " Estudo dos níveis de caroços dos elementos de transição do $5^{\circ}$ período, utilizando espectroscopia de elétrons (XPS, Auger)" Dissertação de Mestrado; UNICAMP, Campinas, SP, 1998.

31. Sayers, D. E.; Stern, E. A.; Lytle, F. W., "New Determination of Amorphous Germanium Structure using X-Ray Absorption Spectroscopy” B. Am. Phys. Soc. 1971, 16: 302.

32. Sayers, D. E.; Stern, E. A.; Lytle, F. W., "New Technique For Investigating Noncrystalline Structures - Fourier Analysis of Extended X-Ray Absorption Fine Structure" Phys. Rev. Lett. 1971, 27: 1204.

33. Hayes, T. M.; Boyce, J. B., "Extended X-Ray Absorption Fine-Structure Spectroscopy" Sol. State Phys. 1982, 37: 173.

34. Wong, J., "Extended X-Ray Absorption FineStructure - A Modern Structural Tool in Materials Science" Mat. Sci. Eng. 1986, 80: 107.

35. Bianconi, A.; Garcia, J.; Benfatto, M., "Topics in Current Chemistry"; Mandelkow, I., Bookbinding (ed); Lüderitz \& Bauer; Berlin, 1988.

36. Koningsberger, D. C., "X-ray Absorption Spectroscopy”; Koningsberger D. C.; Prins R, (ed); John Wiley \& Sons; New York, 1988.

37. Lee, P. A.; Pendry, J. B., "Theory of Extended XRay Absorption Fine-Structure” Phys. Rer. B 1975,
11: 2795.

38. CookJr.,J.W., Sayers, D.E., "Criteria For Automatic X-Ray Absorption Fine-Structure Background Removal” J. Appl. Phys. 1981, 52: 5024.

39. Stern, E. A., "X-ray Absorption, Principles, Apllications, Techniques of EXAFS, SEXAFS and XANES"; Koningsberger, D C. (ed); Jonh Wiley \& Sons, 1988.

40. Tolentino, H.; Cezar, J. C.; Cruz, D. Z.; Compagnon-Cailhol, V.; Tamura, E.; Alves, M. C. M., "Commissioning and First Results of the LNLS XAFS Beamline" J. Synchrotron Radiat. 1998, 5: 521.

41. Gao, XT; Wachs, I. E., "Titania-Silica as Catalysts: Molecular Structural Characteristics and PhysicoChemical Properties" Catal. Today 1999, 51: 233.

42. Ocaña, M.; González-Elipe, A. R., "Preparation and Characterization of Uniform Spherical Silica Particles Coated with $\mathrm{Ni}$ and Co Compounds" Colloid. Surface 1999, 157: 315.

43. Ocaña, M.; Caballero, A.; González-Elipe, A. R.; Tartaj, P.; Serna, C. J., "Valence and Localization of Praseodymium in Pr-Doped Zircon" J. Solid State Chem. 1998, 139: 412.

44. Inumaru, K.; Misono, M.; Okuhara, T., "Structure and Catalysis of Vanadium Oxide Overlayers on Oxide Supports” App. Catal. 1997, 149: 133.

45. Duraud, J. P.; Jollet, F.; Thromat, N.; Gautier, M.; Marie, P.; Legressus, C.; Dartyge, E., "Nonstoichiometry in Pure and Zr-Doped Yttria Ceramics - AN EXAFS AND XPS Study" J. Am. Ceram. Soc. 1990, 73: 2467.

46. Harrison, P. G.; Wood, J. V.; Kelsall, A., "An XPS and EXAFS Study of the Interaction Between Cerium Ions and Glass Surfaces" Phys. Chem. Glasess 2000, 41: 165.

47. Pestryakov, A. N.; Lunin, V. V., "Physicochemical Study of Active Sites of Metal Catalysts for Alcohol Partial Oxidation” J. Mol. Catal. A-Chem. 2000, 158: 325. 
48. Okamoto, Y.; Kubota, T.; Ohto, Y.; Nasu, S., "Physicochemical Characterization of $\mathrm{Fe} / \mathrm{ZrO}_{2}$ Catalysts for NO-CO Reaction” J. Catal. 2000, 192: 412 .

49. Shen, W. J.; Ichihashi, Y.; Okumura, M.; Matsumura, Y., "Methanol Synthesis from Carbon Monoxide and Hydrogen Catalyzed over $\mathrm{Pd} / \mathrm{CeO}_{2}$ Prepared by the Deposition-Precipitation Method" Catal. Lett. 2000, 64: 23.

50. Harrison, P. G.; Lloyd, N. C.; Daniel, W.; Ball, I. K.; Bailey, C.; Azelee, W., "Evolution of Microstructure During the Thermal Activation of Copper(II) and Chromium(III) Doubly Promoted Tin(IV) Oxide Catalysts: An FT-IR, XRD, TEM, XANES/EXAFS, and XPS Study" Chem. Mater. 2000, 12: 3113.

51. Li, H. X.; Wang, W. J.; Li, H.; Deng, J. F., "Crystallization Deactivation of $\mathrm{Ni}-\mathrm{P} / \mathrm{SiO}_{2}$ Amorphous Catalyst and the Stabilizing Effect of Silica Support on the Ni-P Amorphous Structure" J. Catal. 2000, 194: 211.

52. Baker, S. H.; Bayliss, S. C.; Gurman, S. J.; Elgun, N.; Batest, J. S.; Davis, E. A., "The Effect of Varyning Substrate-Temperature on the Structural and Optical-Properties of Sputtered Gaas Films" J. Phys-Condens. Mat. 1993, 5: 519.

53. Mangat, P. S.; Huttel, Y.; Schirm, K. M.; Hurych, Z.; Soukiassian, P., "Photoemission Extended X-RAY-Absorption Fine-Structure (PEXAFS) - A New Approach to Probe Surface and Interface Atomic Geometry" J. Phys. IV 1994, 4: c9-461.

54. Wang, Z.; Goeller, P. T.; Boyanov, B. I.; Sayers, D. E.; Nemanich, R. J., "An Integrated Growth and Analysis system for in-situ XAS Studies of MetalSemiconductor Interactions" J. Phys. IV 1997: c2561.

55. Leroux, F.; Piffard, Y.; Ouvrard, G.; Mansot, J.-L.; Guyomard, D., "New Amorphous Mixed Transition Metal Oxides and their Li Derivatives: Synthesis, Characterization, and Electrochemical Behavior" Chem. Mat. 1999, 11: 2948.

56. Meng, M.; Lin, P. Y.; Fu, Y. L., "The Catalytic Removal of $\mathrm{CO}$ and $\mathrm{NO}$ over $\mathrm{Co}-\mathrm{Pt}(\mathrm{Pd}, \mathrm{Rh}) /$ gamma- $\mathrm{Al}_{2} \mathrm{O}_{3}$ Catalysts and their Structural Characterizations" Catal. Lett. 1997, 48: 213.

57. Gonçalves, J. E.; Castro, S. C.; Ramos, A.Y.;Alves, M. C. M.; Gushikem, Y., "X-RAY Absorption and XPS Study of Titanium Mixed Oxides Synthesized by the Sol-Gel Method" J. Electron Spectrosc. 2001, 114: 307.

58. Fernández, A.; Caballero, A.; González-Elipe, A. R.; Herrman, J. M.; Dexpert, H.; Villain, F., "InSitu EXAFS Study of The Photocatalytic Reduction and Deposition of Gold on Colloidal Titania” J. Phys. Chem. 1995, 99: 3303.

59. Vayssilov, G. N., "Structural and Physicochemical Features of Titanium Silicalites" Catal. Rev. 1997, 39: 209

60. Davis, R. J.; Liu, Z., "Effects of Structure and Composition on Catalysis by Ti-Si Mixed Oxides" Abstr. Pap. Am. Chem. S. 1997, 213: 274.

61. Blasco,T.;Camblor,M.A.;Fierro,J.L.G.;Pariente, J. P., "The State of $\mathrm{Ti}$ in Titanoaluminosilicates Isomorphous with Zeolite-Beta" J. Am. Chem Soc. 1993, 115: 11806.

62. Francisco, M.S.P.; Nascente, P. A. P.; Mastelaro, V. R.; Florentino, A. F., "X-RAY Photoelectron Spectroscopy, X-RAY Absorption Spectroscopy, and X-RAY Diffraction Characterization of $\mathrm{CuO}-\mathrm{TiO}_{2}-$ $\mathrm{CeO}_{2}$ Catalyst System" J. Vac. Sci. Soc. Technol. A 2001, 19: 1150 .

63. Francisco, M.S.P.; Mastelaro, V. R.; Florentino, A. F.; Bazin, D., "Structural Study of Copper Oxide Supported on a Ceria-Modified Titanic Catalyst System” Top. Catal. 2002, 18: 105.

64. Li, H.; Li, H.X.; Dai, W. L.; Wang, W.J.; Fang, Z.G; Deng,J. F., "XPS Studies on Surface Electronic Characteristics of Ni-B and Ni-P Amorphous Alloy and its Correlation to their Catalytic Properties" Appl. Surf. Sci. 1999, 152: 25.

65. Kusama, H.; Bando, K. K.; Okabe, K.; Arakawa, H., "Effect of Metal Loading on CO2 Hydrogenation Reactivity over $\mathrm{Rh} / \mathrm{SiO}_{2}$ Catalysts” Appl. Catal. AGen. 2000, 197: 255. 
66. Gonçalves, J. E., "Estudo, caracterização, propriedades e aplicações do óxido binário $\mathrm{SiO}_{2} / \mathrm{TiO} 2$ e antimonatos dos óxidos binários $\mathrm{SiO}_{2} / \mathrm{TiO}_{2}$ ” Tese de Doutorado; UNICAMP, Campinas, SP, 2000.

\section{Glossário de termos e definições}

1- Espectroscopia no infravermelho (IR): A região de infravermelho (infrared, IR) do espectro eletromagnético corresponde a região de comprimento de onda de 0,78 a $1000 \mu \mathrm{m}$ ou número de onda de 12.800 a $10 \mathrm{~cm}^{-1}$ (unidade usualmente usada), sendo utilizada em estudos envolvendo rotação e vibração de moléculas. Do ponto de vista de aplicação e instrumentação, a região de infravermelho é dividida em três regiões distintas: near infrared (próximo - 12.800 a $4.000 \mathrm{~cm}^{-1}$ ), mid infrared (médio - 4.000 a $200 \mathrm{~cm}-1$ ) e far infrared (afastado - 200 a $\left.10 \mathrm{~cm}^{-1}\right)$. A região do near infrared é usualmente utilizada para análise quantitativa de materiais sólidos, líquidos e misturas gasosas, enquanto que a do mid infrared, além de ser utilizada na análise quantitativa de complexos gasosos, líquidos ou misturas sólidas, também é utilizada na determinação qualitativa de sólidos, líquidos ou gases. A região do far infrared é utilizada na análise qualitativa de compostos inorgânicos ou espécies organometálicas.

2- Espectroscopia paramagnética eletrônica (EPR): A ressonância paramagnética eletrônica, RPE (electronic paramagnetic ressonance, EPR), também conhecida como ressonância do spin eletrônico (electronic spin ressonance, ESR) é o nome dado ao processo de absorção ressonante de microondas por átomos, íons ou moléculas paramagnéticas, com ao menos um elétron desemparelhado, e na presença de um campo magnético estático. A EPR foi descoberta por Zavoiski em 1945. Ela tem uma ampla gama de aplicações em química, física, biologia, e medicina. É usada para mapear a distribuição de um elétron desemparelhado em uma molécula, fornecendo várias informações sobre os níveis de energia de complexos. Pode comprovar a estrutura estática de sistemas sólidos e líquidos, e é também muito utilizada no estudo de processos dinâmicos. Os espectrômetros mais comuns trabalham na faixa de $9-10 \mathrm{GHz}$ (banda X). No entanto, o desenvolvimento da eletrônica tem facilitado o aparecimento de espectrômetros trabalhando em faixas de freqüências de centenas de $\mathrm{MHz}$ até centenas de $\mathrm{GHz}$.

3- Espectroscopia eletrônica de Auger: é uma técnica de análise de superfície extremamente sensível que permite que camadas superficiais de um material sejam examinadas com exelente resolução da profundidade. Isto é possível porque os elétrons Auger de camadas mais externas dos átomos do átomo que compõe o sólido sobrevivem para serem ejetados e medidos, sem serem espalhados inelasticamente.

4-Espectroscopia fotoeletrônica no ultravioleta(UPS): tanto a técnica de XPS quanto a de UPS se baseiam nas análises das energias dos elétrons de um sólido quando irradiados por raios-X e ultravioleta (10-45 eV) monoenergéticos, respectivamente. Com a técnica UPS pode-se estudas os elétrons dos níveis mais externos, em particular da banda de valência.

\section{5-Espectrometria de massa deíonssecundários(SIMS):} esta técnica éuma das mais sensíveis das técnicas-analíticas comumente utilizadas devido a inerente sensibilidade associada às técnicas baseadas em espectroscopia de massa. Por SIMS, a superfície da amostra é sujeita ao bombardeamento de íons de alta energia, o que leva a ejeção tanto de espécies neutra e carregada de superfície. As espécies ejetadas incluem átomos, aglomerados de átomos (cluster) e fragmentos moleculares.

\section{6- Espectrometria de massa de microssonda laser} (LMMS): este tipo de espectroscopia usa um feixe pulsado de fótons para evaporar a amostra em uma pequena região (diâmetro próximo a $0,5 \mu \mathrm{m}$ ). A fração de átomos evaporados é ionizada por um feixe de laser, acelerado a uma energia cinética de $3 \mathrm{keV}$, e então analisado por meio de um espectrômetro de massa. Este instrumento fornece a detecção de todos elementos e isótopos. As aplicações típicas incluem analises de partículas de diâmetro próximo a $200 \mathrm{~nm}$, a análise de frações finas biológicas e células, e de traços de materiais.

7- Microssonda eletrônica (EM): o método emprega uma microssonda eletrônica, onde a emissão de raios-X é estimulada na superfície da amostra por um feixe fino e focalizado de elétrons. A emissão de raios- $X$ resultante é detectada e analisada por um espectrômetro dispersivo de comprimento de onda ou de energia.

8- Métodos microscópicos: A potência amplificadora de um microscópio óptico é limitada pelo comprimento da onda de luz visível. O microscópio eletrônico utiliza elétrons para iluminar um objeto. Como os elétrons têm um comprimento de onda muito menor do que o da luz, podem mostrar objetos muito menores. O comprimento de onda dos elétrons utilizado nos microscópios eletrônicos é de cerca de 0,5 angströms. Há dois tipos básicos de microscópios eletrônicos: o microscópio eletrônico de transmissão (Transmission Electron Microscope, TEM) 
e o microscópio eletrônico de varredura (Scanning Electron Microscope, SEM). Um TEM dirige o feixe de elétrons para o objeto que se deseja aumentar. Uma parte dos elétrons atravessa o objeto, formando uma imagem aumentada. Para utilizar um TEM, é preciso cortar a amostra em camadas finas. Os microscópios eletrônicos de transmissão podem aumentar um objeto em até um milhão de vezes. Um microscópio eletrônico de varredura cria uma imagem ampliada da superfície do objeto. Não é necessário cortar um objeto para observálo com um SEM (pode ser colocado no microscópio sem grandes preparativos). O SEM explora a superfície da imagem ponto por ponto, ao contrário do TEM, que examina uma grande parte da amostra de cada vez. Seu funcionamento se baseia em percorrer a amostra com um feixe muito concentrado de elétrons, de forma parecida com a varredura de um feixe de elétrons na tela de um aparelho de televisão. Os microscópios eletrônicos de varredura podem ampliar os objetos 100 mil vezes ou mais. Esse tipo de microscópio é muito útil porque, ao contrário dos TEM ou dos microscópios ópticos, produz imagens tridimensionais realistas da superfície do objeto

9- Microscopia de tunelamento de varredura (STM): A conceituação básica da STM (do inglês, scanning tunneling microscopy) é o princípio físico do tunelamento eletrônico. Este efeito quântico, previsto na década de 20, ocorre entre dois condutores separados por uma camada isolante suficientemente fina, ou seja, na presença de uma barreira de potencial. A corrente de tunelamento é uma medida da superposição das funções eletrônicas dos dois condutores. Fundamental para a operação do STM é a extrema sensibilidade da corrente de tunelamento à separação entre os eletrodos. No STM, uma sonda muito fina, e muito próxima da amostra, varre a sua superfície, registrando o seu relevo (potencial). Sua realização, simples em princípio, depende de considerável astúcia experimental. O STM só é aplicável a amostras condutoras, podendo ser utilizado tanto no vácuo como na atmosfera.

10-Microscopiadeforçaatômica(AFM): Emmicroscopia de força atômica (do inglês, atomic force microscopy) uma pequena ponta de dimensões quase atômicas é varrida sobre uma superfície, condutora ou não, ao mesmo tempo em que forças de interação, repulsivas ou atrativas, entre os átomos da ponta e os átomos das primeiras camadas da superfície são monitoradas e graficadas para a formação da imagem de AFM. O AFM é extremamente sensível a qualquer perturbação local que afete as forças de interação entre ponta e superfície. Um dos fatores fundamentais em AFM é saber exatamente qual a força normal aplicada pela pequena ponta do microscópio sobre a superfície de maneira a evitar que a superfície seja danificada elasticamente ou até mesmo plasticamente pela ponta do AFM. Além do mais, sem o conhecimento da força normal aplicada entre ponta e superfície é praticamente impossível a obtenção de qualquer informação física quantitativa tal como coeficiente de atrito de superfícies das imagens de AFM.

11- Luz síncrotron: A expressão indica o tipo de luz produzida por um equipamento que pode ser chamado síncroton. Esta luz é a mesma que os nossos olhos podem ver, só que ampliada para regiões do espectro eletromagnético que a visão não consegue perceber. $\mathrm{O}$ síncrotron pode produzir todas as "luzes" do espectro, aí incluídos a ultravioleta e os raios-X, necessárias para realização de pesquisas materiais.

\section{ESPECTRO ELETROMAGNÉ TICO}

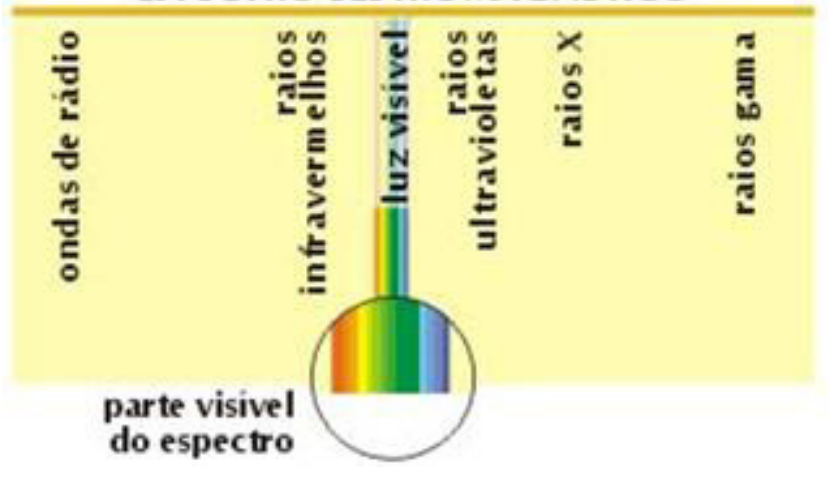

Espectro eletromagnético (fonte: www.lnls.br)

12- Eletronvolt $(\mathbf{e V}): 1 \mathrm{eV}=1,6021 \times 10 \mathrm{~J}$; caloria (cal): 4,1 J. A unidade recomendada pela IUPAC é o Joule (J), mas em trabalhos envolvendo Raios-X a utilização do termo eletronvolt ainda é bastante comum.

Ângstron $(\AA): 1 \AA=10^{-10} \mathrm{~m}$. A unidade recomendada pela IUPAC é o nanometro $(\mathrm{nm})$.

13- Bomba de difusão: É constituída por um invólucro cilíndrico, dentro do qual existem um vaporizador para o líquido da bomba e sobre este uma chaminé que conduz o vapor aos vários andares de ejetores. As moléculas do vapor do fluido ao saírem dos ejetores arrastam as moléculas do gás existentes dentro da bomba para baixo e de encontro às paredes da bomba. Como estas são arrefecidas, por circulação de água ou ar, dá-se uma condensação do fluido que volta ao vaporizador. $\mathrm{O}$ gás arrastado é comprimido na parte inferior, de onde é retirado pela bomba rotatória associada à bomba de difusão.Os líquidos utilizados nas bombas de difusão são o mercúrio ou óleos especiais de muita baixa tensão de vapor.Sempre que se usa mercúrio é necessário colocar um trap de nitrogênio líquido entre a bomba e o volume a bombear para condensar o vapor de mercúrio. 
14- Bomba turbo-molecular: Esta bomba trabalha comprimindo o gás através de suas pás de alta velocidade, isto é, há uma transferência de momento das pás giratórias para as moléculas do gás. O rotor gira com velocidade de 24.000 a $60.000 \mathrm{rpm}$. Teve sua operação inicializada por W. Becker em 1958. [http://www.fis.unb.br/plasma/ bomba2.htm].

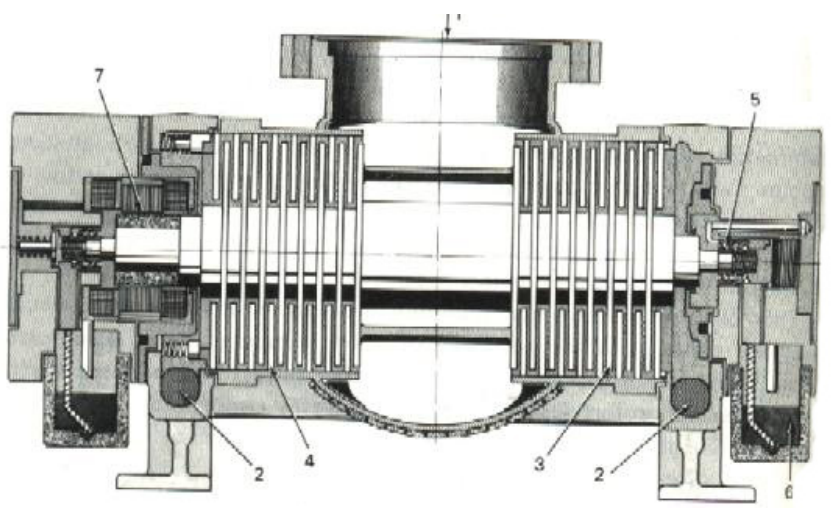

Esquema de uma bomba turbo-molecular

1. Entrada, 2. Saída, 3. Discos do Rotor, 4. Discos de estamento, 5. Conexão, 6. Reservatório de óleo, 7. Motor

15-Air-lock: Câmara hermética, usualmente localizada entre duas regiões de pressões diferentes, na qual a pressão pode ser regulada.

16- Detector de elétrons tipo channeltron: Um detector tipo channeltron convencional geralmente consiste de um tubo capilar de vidro onde se cria sobre sua superfície interna uma camada altamente resistiva e boa emissora de elétrons secundários. Através de aplicação de uma diferença de potencial da ordem de $3000 \mathrm{~V}$ entre as extremidades aparece um gradiente de potencial que faz com que qualquer elétron que se choque com a superfície interna próximo ao extremo negativo, com energia suficiente para emitir elétrons secundários dará inicio a uma cascata que ira se multiplicando ao longo do tubo por ação da diferença de potencial aplicado, gerando um pulso de corrente na saída tubo. A construção deste tipo de dispositivo é muito difícil e apenas duas ou três indústrias o fazem mundialmente.

\section{7- Processos de espalhamento múltiplos e simples:}

(a) XANES

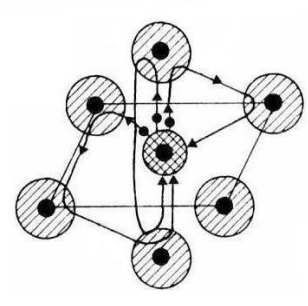

(b) EXAFS

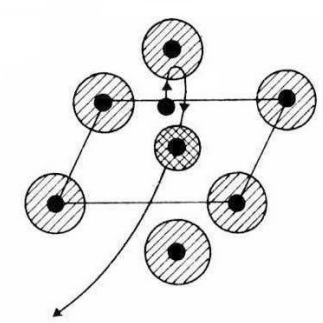

$\longrightarrow$ Trajetória do fotoelétron
Esquema dos espalhamentos: (a) espalhamentos múltiplos no regime XANES e (b) espalhamento simples no regime de EXAFS [Bianconi, A.; Garcia, J.; Benfatto, M. in: XANES in Condensed Systems, in Synchrotron Radiation in Chemistry and Biology I, ed. Mandelkow, I., p. cm. - (Topics in Current Chemistry; 145), ed. Bookbinding: Lüderitz \& Bauer, berlin, 1988.].

18- Campo de Coulomb: é o campo elétrico ao redor de uma partícula ou carregada.

19-Velocidade da luz novácuo(c): Em 1983, uma medida da velocidade da luz usando lasers, feita pelo Bureau Nacional de Padrões dos Estados Unidos, achou, como resultado, c $=299.792,4586 \mathrm{~km} / \mathrm{s}$, com incerteza de mais ou menos $0,0003 \mathrm{~km} / \mathrm{s}$. A partir desse ano, por decisão dos órgãos científicos internacionais, a velocidade da luz passou a ser considerada uma constante universal com valor bem determinado, exatamente igual a 299.792,458 $\mathrm{km} / \mathrm{s}$.

20- Constante de Plank: Plank deduziu que a energia de um feixe de fótons (partículas de luz segundo Einstein) era proporcional à freqüência da radiação (a mesma conclusão a que Einstein chegaria, 5 anos mais tarde), e que a constante de proporcionalidade valeria algo em torno de $6 \times 10^{-34} \mathrm{~J} \mathrm{~s}$, valor hoje conhecido como h, a Constante de Plank: $\mathrm{E}_{\text {fóton }}=\mathrm{h} v$ (Energia diretamente proporcional à freqüência da onda)

21- Regra de Ouro de Fermi: esta fornece a probabilidade de transição entre um estado inicial e um estado final de um sistema, sendo que esta transição pode ser atômica, decaimento nuclear, espalhamento entre outros tipos de transições físicas.

22- Janela de Kapton: esta janela tem a função de bloquear a radiação indesejável na amostra.

Número de coordenação: é o número de ligantes na esfera de coordenação primária, que num complexo consiste de um conjunto destes ligantes diretamente ligados a um íon central.

23- Coordenação octaédrica: neste tipo de coordenação o número de ligantes é seis e estão distribuídos conforme mostrado na figura.

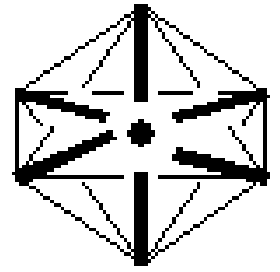

Complexo de coordenação octaédrico. 
24- Estrutura espinélio: de fórmula geral $\mathrm{AB}_{2} \mathrm{O}_{4}$, esta estrutura consiste de uma rede fcc de íons $\mathrm{O}_{2}^{-}$nas quais os íons $\mathrm{A}$ residem em um oitavo dos buracos tetragonais e os íons B em metade dos buracos octaédricos.

25- Anatase: Uma das formas naturais do dióxido de titânio $\left(\mathrm{TiO}_{2}\right)$. As outras duas formas são o rútilo e a brookite, sendo o primeiro o mais comum. A anatase é tetragonal, apresentando, com freqüência, hábito bipiramidal, pseudo-octaédrico. Oferece diversas cores castanhas, azuladas, negras e lustre adamantino ou quase metálico. Dureza superior à do vidro e índices de refração muito elevados. A anatase aparece, habitualmente, como mineral secundário, proveniente da alteração de outros minerais titaníferos. É conhecida, como elemento acessório, em vários tipos de rochas: granitos, gnaisses, xistos cristalinos etc.

26- Zeolitas: são silicatos do tipo "open-framework" compostas de tetraedros de $\mathrm{SiO}_{4}$ e $\mathrm{AlO}_{4}$, os quais estão conectados a outros cátions, o que garante a neutralidade elétrica da estrutura. A estrutura de canais resultante permite que esses materiais sejam "peneiras moleculares" eficientes. Além disso, tem-se demonstrado que as zeólitas agem como "trocadores de íons", adsorventes e catalisadores. 